\title{
Review on the Development, Control Method and Application Prospect of Brake-by-Wire Actuator
}

\author{
Xiaoxiang Gong ${ }^{1, *}$, Weiguo Ge ${ }^{2}$, Juan Yan ${ }^{3}$, Yiwei Zhang ${ }^{2}$ and Xiangyu Gongye ${ }^{1}$ \\ 1 College of Mechanical Engineering, Chongqing Three Gorges University, 666 Tianxing Street, \\ Wanzhou District, Chongqing 404000, China; xiangyugongye@gmail.com \\ 2 Chongqing Engineering Research Center for Advanced Intelligent Manufacturing Technology, \\ Chongqing Three Gorges University, 666 Tianxing Street, Wanzhou District, Chongqing 404000, China; \\ 20090009@sanxiau.edu.cn (W.G.); ywzhang@sanxiau.edu.cn (Y.Z.) \\ 3 Chongqing Engineering Technology Research Center for Light Alloy and Processing, \\ Chongqing Three Gorges University, 666 Tianxing Street, Wanzhou District, \\ Chongqing 404000, China; 20140048@sanxiau.edu.cn \\ * Correspondence: gongxiaoxiang@sanxiau.edu.cn; Tel.: +86-023-5810-5722
}

Received: 12 February 2020; Accepted: 4 March 2020; Published: 5 March 2020

check for updates

\begin{abstract}
This paper reviews and summarizes the development, key technologies, and application of brake-by-wire (BBW) actuators. BBW is the technology orientation of future vehicle brake system. The main feature of BBW is to replace some of the mechanical and hydraulic components of traditional brake system with electronic control components, and use cables and wires to transmit energy and signals. BBW actuators have outstanding advantages, such as fast response, accurate control, and compact structure. They are easy to integrate with active safety functions and they are easily matched with the regenerative braking systems of electric vehicle. First, this paper summarizes the classification, characteristics, performance, and architecture of BBW actuators. Subsequently, the braking process regulation of vehicle is considered to be the main target, which is summarized from two aspects of actuator regulation and braking force distribution. The state estimation algorithm and control algorithm applied to these actuators are summarized and analyzed, and the development trend, challenges, and schemes of the braking force distribution are proposed. The development and research trend of braking force match strategies between the regenerative brake system and BBW system are also analyzed and summarized. The further electrification and intelligence of vehicle demand BBW's braking force control method and distribution method must have higher control accuracy, stronger robustness, and wider adaptability, and the effects on braking comfort and handling stability must be further discussed.
\end{abstract}

Keywords: brake-by-wire; braking force control; wheel anti-lock control; regenerative brake strategy; braking force distribution strategy

\section{Introduction}

The hydraulic brake system is mature and reliable, and it has been widely used in various vehicles. The anti-lock brake system (ABS) is considered as a landmark invention of braking systems. Since then, the braking force distribution system (EBD), traction control system (TCS), yaw stability control (YSC), electronic stability program (ESP), advanced driver assistant system (ADAS), and automatic emergency brake (AEB) are gradually invented and integrated into hydraulic brake systems [1].

Figure 1 summarizes the development history and future trends of the braking system in terms of safety and comfort. It can be seen that the safety performance and ride comfort have been greatly improved, with the continuous improvement of braking system and the continuous integration of 
new features [2,3]. The additional functions, such as ABS and ESP, require additional devices, such as high-speed solenoid valves, oil return pumps, and return lines. Therefore, the structure of hydraulic brake system is becoming increasingly complex, and the maintenance is also becoming more and more difficult [4,5]. At present, new energy vehicles, such as electric vehicles (EV), hybrid electric vehicles (HEV), and fuel cell electric vehicles (FCEV), are developing rapidly and are highly concerned by major automotive manufacturers. However, most electric vehicles still use hydraulic brake system. On the one hand, the electric vehicles cannot use vacuum boosters to provide auxiliary force. The electric hydraulic pump must first be used to increase the hydraulic pressure, and then delivers the high pressure to each wheel. The electric energy needs to be converted and then transmitted multiple times in this process, so the energy utilization efficiency is not high, and there is the potential danger of brake fluid leakage. On the other hand, the hydraulic brake system cannot accurately and independently regulate the braking force, so it cannot be well matched with the regenerative brake system of EV and HEV [6].

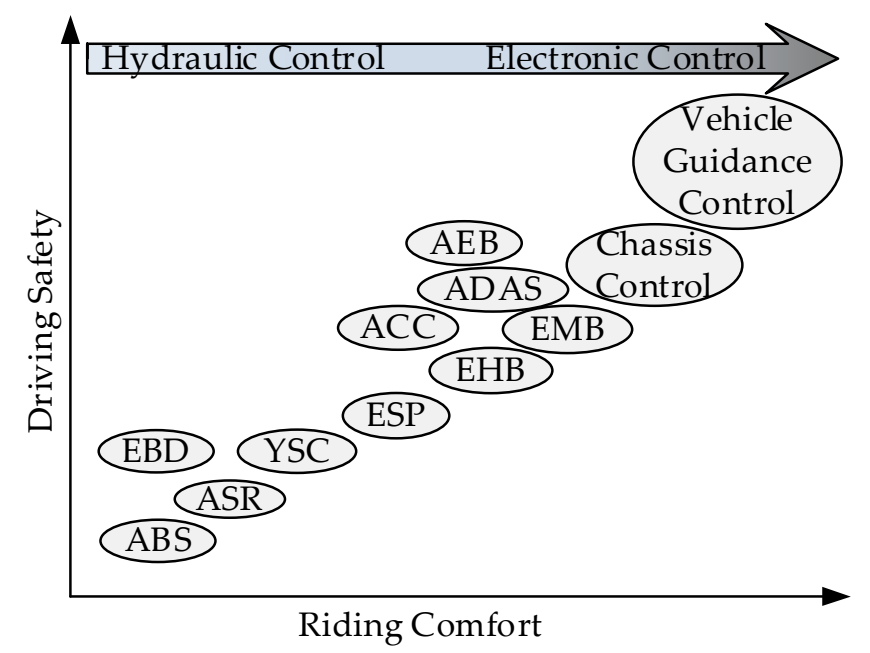

Figure 1. Development history and trend of vehicle brake system.

It is particularly important to research and develop new brake system that match well with the regenerative brake system of EV. The brake-by-wire (BBW) systems, as represented by electro-hydraulic brake (EHB) and electro-mechanical brake (EMB), have the advantages of simple structure, comprehensive functions, and reliable performance, and they have been studied by many researchers for many years. In particular, each wheel actuator of EMB is powered by a separate motor, which greatly improves the braking flexibility and braking safety.

The BBW are new types of actuator that are essentially different from hydraulic brake. Figure 2 briefly illustrates the differences between the BBW and traditional hydraulic brake, as well as the performance comparison in terms of performance, modularity, driving pleasure, ergonomics, safety, and efficiency. In the hydraulic brake system, the brake actuator and brake pedal are fixedly connected by mechanical and hydraulic components, so the flexibility is poor. However, the BBW actuators are driven by separated electric motor, and cables and wires transmit the signals and energy, which greatly improves the response speed, braking efficiency, and flexibility. Therefore, BBW is superior to hydraulic brake in terms of braking performance, modularity, energy efficiency, and so on [7]. 


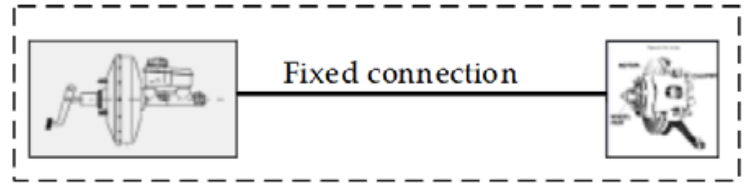

(a) Hydraulic brake

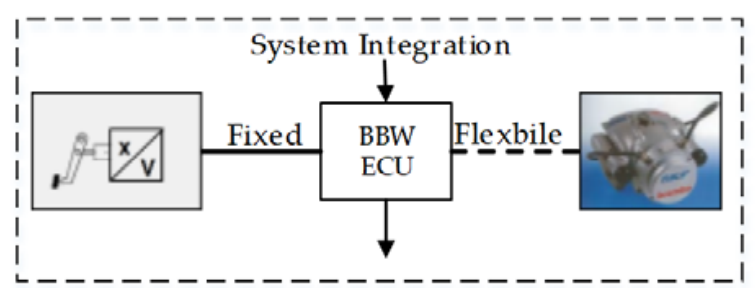

(b) Brake-by-wire

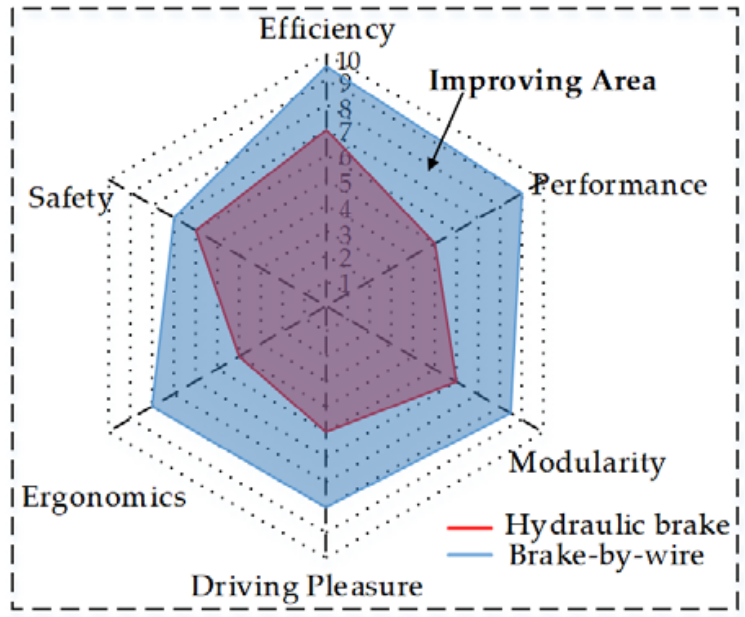

(c) Performance comparison

Figure 2. The structure and performance of hydraulic brake and brake-by-wire (BBW).

\section{Classification and Key Technologies of BBW}

The BBW technology was first applied to aircraft. The first BBW actuator was proposed by United States in 1979, and then tested on A-10 attack aircraft in 1982. After nearly 40 years of research, various BBW actuators and systems for vehicles have been developed, including electro-hydraulic brake (EHB), electro-mechanical brake (EMB), electro-wedge brake (EWB), and so on [8].

\subsection{Classification and Structure of Brake by Wire Actuator}

\subsubsection{Electro-Hydraulic Brake}

Electro-hydraulic brake (EHB) is an evolution of the traditional hydraulic brake system. It is a typical integrated system of mechanical components, hydraulic systems, and electronic control systems. Figure 3 shows the structure and composition of EHB. It mainly consists of two parts: hydraulic actuators and electronic control systems. The hydraulic actuators include high pressure accumulator, hydraulic pump, high oil pipes and low oil pipes, liquid accumulator, solenoid valves, and so on; the electronic control systems includes sensors, electronic control unit (ECU), drive motors, cables, and so on [9].

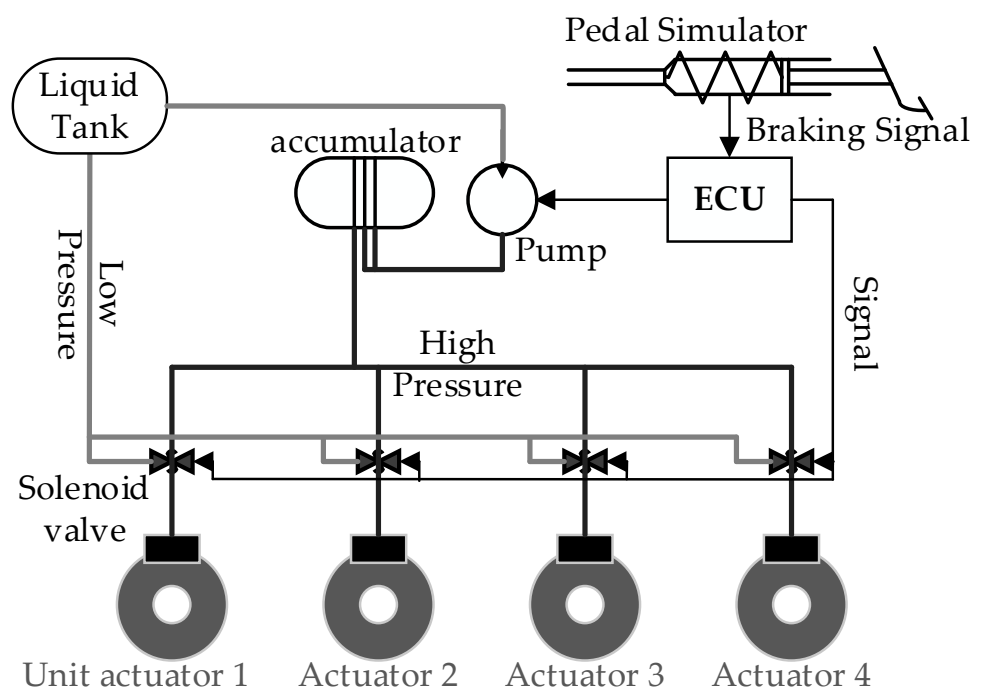

Figure 3. The structure and composition of electro-hydraulic brake (EHB). 
EHB replaces some mechanical parts with electronic components and solenoid valves. In particular, the electronic pedal simulator replaces the traditional brake pedal [10]. The sensor on the pedal simulator converts the pedal stroke or pedal force into electronic signal and then transmits it to the ECU. The corresponding sensors and feedback to the ECU also sample the velocity, wheel speed, wheel cylinder pressure, and other signals. The control signals are generated and transmitted to the high-speed solenoid valves to regulate the hydraulic pressure after all of the sensor signals are calculated and analyzed by the ECU. When the wheel cylinder needs to be pressurized, the inlet valve is opened, the outlet valve is closed, so the high pressure fluid enters the cylinder from the accumulator. When the wheel cylinder pressure needs to be maintained, both of the valves are closed. When the wheel cylinder needs to be decompressed, the inlet valve is closed, the outlet valve is opened, and the fluid in the wheel cylinder flows back to liquid reservoir [11,12].

EHB has excellent performance when compared with the traditional hydraulic brake system, and it is more mature in technology as compared with electro-mechanical brake (EMB), so it has good development prospects in the short term [13]. However, the braking performance of EHB is not as good as EMB, due to the presence of hydraulic components in the EHB, such as hydraulic pump, high-pressure accumulator, high-pressure pipelines, and liquid reservoir. Therefore, the EHB will eventually be replaced by EMB, EWB, or other more advanced brake systems [14].

\subsubsection{Electro-Mechanical Brake}

Like other X-by-wire systems in vehicles, the actuator and controller of electro-mechanical brake (EMB) are completely new designed, so that the performance of EMB is much better than EHB [15]. EMB uses a motor to provide the driving torque, uses a gear mechanism or planetary gears to amplify the torque, and uses ball-screw mechanism to convert torque into force, as shown in Figure 4 [16,17]. From the two figures, it can be seen that EMB is a new type of promising brake actuator, with the advantages of high transmission efficiency, environmental protection, and energy saving, because it completely eliminate the hydraulic components, such as hydraulic pumps and solenoid valves [18].

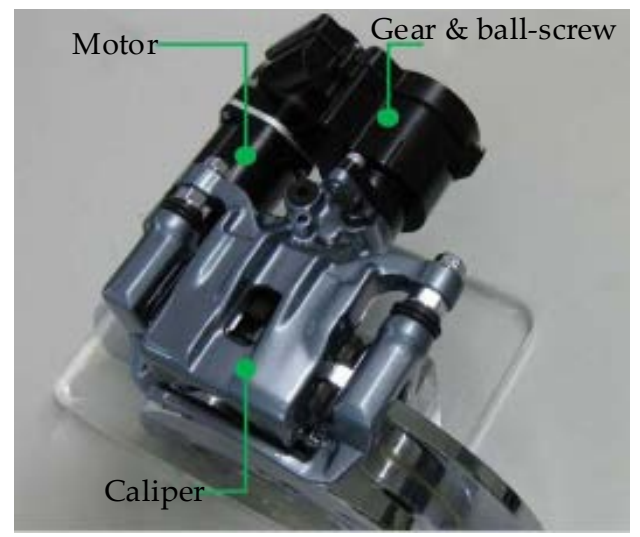

(a) Prototype

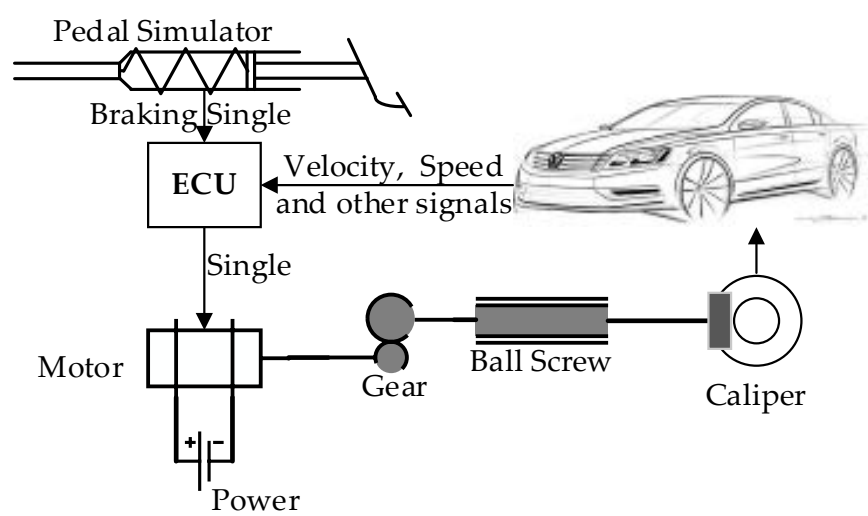

(b) Principle

Figure 4. Electro-mechanical brake.

The specific braking process is as follows $[19,20]$. The ECU controls the rotation of the motor after receiving the brake single, and it drives the gear reduction mechanism and ball screw mechanism, so that the screw moves to push the friction plate and eliminates the brake clearance between the friction plate and brake disc. The motor will be blocked after all fit clearances and brake clearances are completely eliminated (the friction plate is in close contact with the brake disc). Thereafter, the motor torque is amplified by the gear mechanism and converted into an axial force by the ball-screw mechanism, and then the force finally acts on the brake disc and reduces the wheel speed. If the brake needs to be removed, the motor reverses and drives the ball screw back to its original position. Finally, 
the spring force pushes the friction plate back to the initial position, and an appropriate clearance is maintained between the brake disc and friction plate [21,22].

EMB is considered the main form of future brake system, but it still needs to solve many key problems. For example, EMB actuators need to provide a maximum caliper clamping force of $40 \mathrm{kN}$ to provide sufficient braking force [23]. EMB works in harsh conditions, such as cold, hot, muddy water, vibration, and electromagnetic interference, and the motor is usually blocked, which are great challenges in the design and control of EMB [24]. In addition, the 48V vehicle battery, reliability, fault tolerance, and anti-disturbance issues also require technical breakthroughs, so it has not been widely used.

\subsubsection{Electro-Wedge Brake}

EWB uses the wedge-shaped self-exciting effect to obtain sufficient clamping force, which Siemens first introduced, as shown in Figure $5[25,26]$. Like EMB, EWB also uses torque motor to provide driving force; unlike EMB, the force amplification structure of EWB is wedge-shaped self-amplifying mechanism, rather than gear mechanism $[27,28]$. After the motor enters the block state, the motor torque is first converted into force by ball screw mechanism, and then the wedge-shaped self- amplifying mechanism enlarges the force to slow the wheel down [26,29].

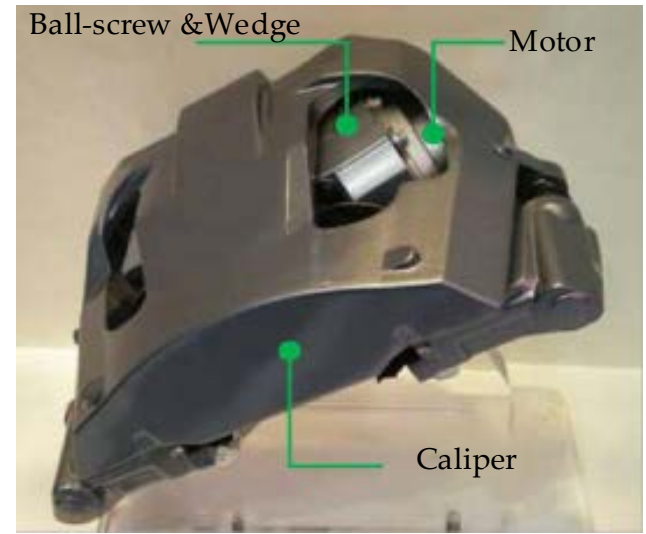

(a) Prototype

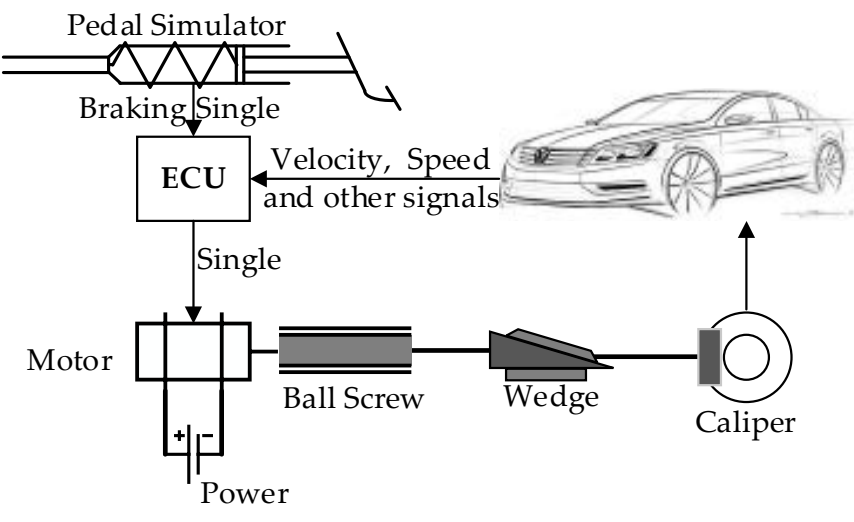

(b) Principle

Figure 5. Electronic-wedge brake.

There are two types of EWB: upper wedge and lower wedge, as shown in Figure 6 [30]. In the upper wedge structure, the braking force is obtained by inserting the upper wedge, the direction of the ball screw force is the same as the friction force that is applied to the brake disc, and the friction force pulls the wedge block. Therefore, only a small force is required to control the braking force. In the lower wedge structure, the ball screw exerts the force in the direction opposite the frictional force, thus reducing the self-reinforcing effect. In addition, a large force is also required to remove the wedge from the space between the disc and roller when the wedge is stuck, so the braking process is difficult to control. In summary, the upper wedge is more practical, and most of the research is carried around it.

In the brake disc clamping scheme, most of the researchers choose to clamp the side of disc. However, the circumferential clamping scheme of brake disc is discussed in literature [31], which has better heat dissipation capacity and better braking efficiency than the side clamping method. Literature [25] also discusses non-circular gear transmission for EWB to avoid potential hazards due to the contamination of moving parts under very harsh operating conditions. 


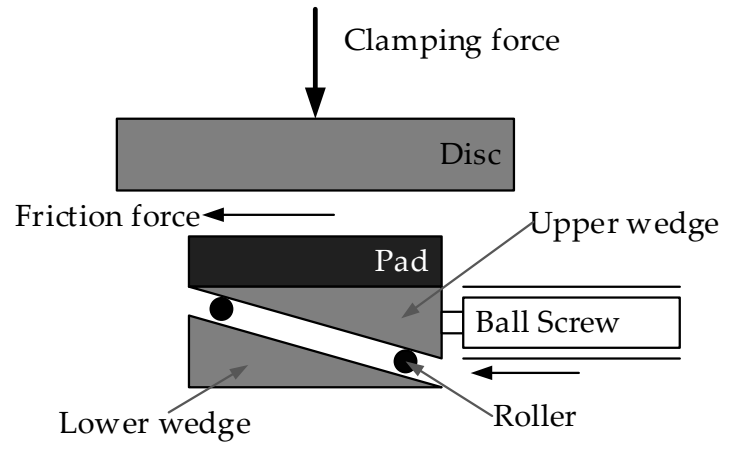

(a) Upper-wedge-type

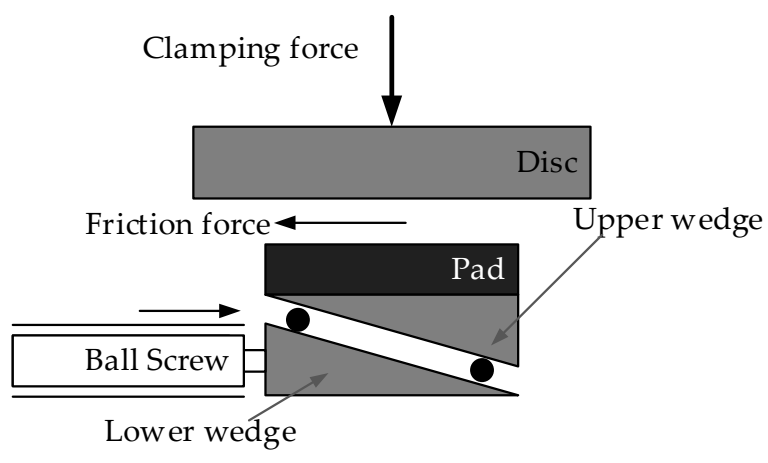

(b) Lower-wedge-type

Figure 6. Upper-wedge electro-wedge brake (EWB) and lower-wedge EWB.

\subsubsection{Hybrid Brake-by-Wire Actuator}

EMB and EWB are the main BBW actuators currently under study. They do not have any hydraulic components and maintain good technical prospects. However, they have not been widely promoted and applied due to the limitation of motor technology and reliability. Therefore, Ricardo de Castro designed a hybrid BBW actuator that was composed of hydraulic system and electromechanical system, as shown in Figure 7. The hybrid actuator combines the advantages of EMB and hydraulic system, and it has good prospects in the short term [32,33]. The main structure and components of the hybrid actuator are similar to EMB, which also has motor, gear mechanism, and ball screw mechanism. The difference is that the hydraulic cylinder is also used to further increase the braking force. After the motor torque is amplified by the gear mechanism, it is converted into axial force by the ball screw mechanism, and then the force pressurizes the brake fluid in the master cylinder. Finally, the pressure is transmitted to the wheel cylinder through the high pressure pipeline [34-36].

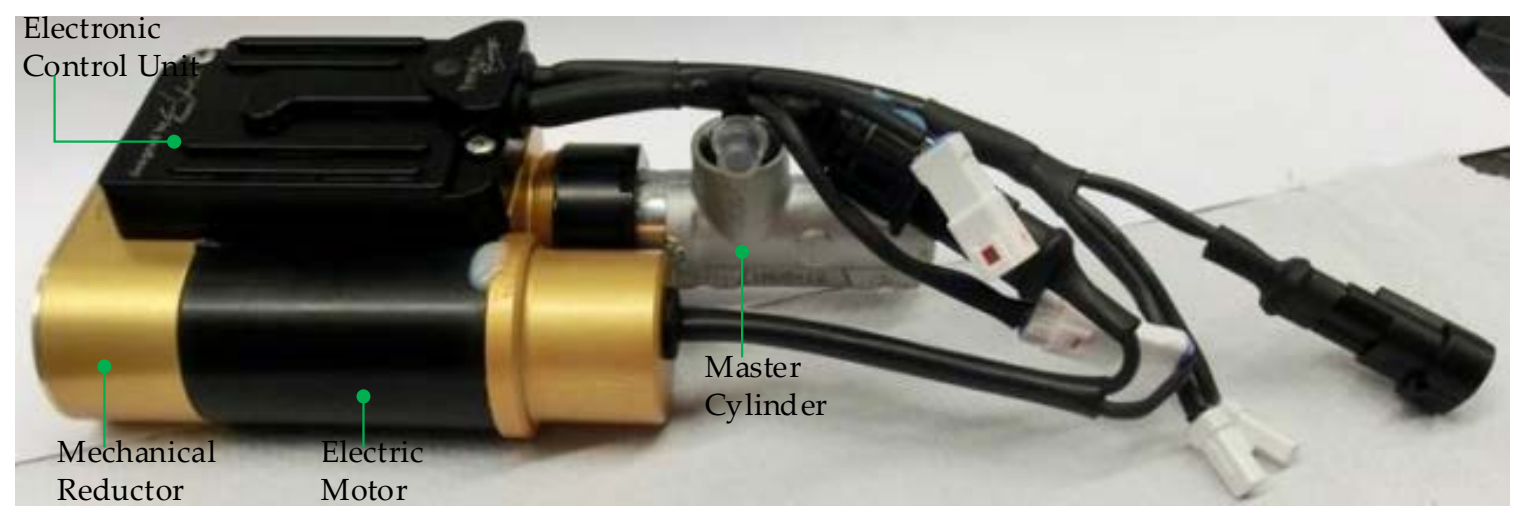

(a) Prototype of hybrid brake-by-wire actuator

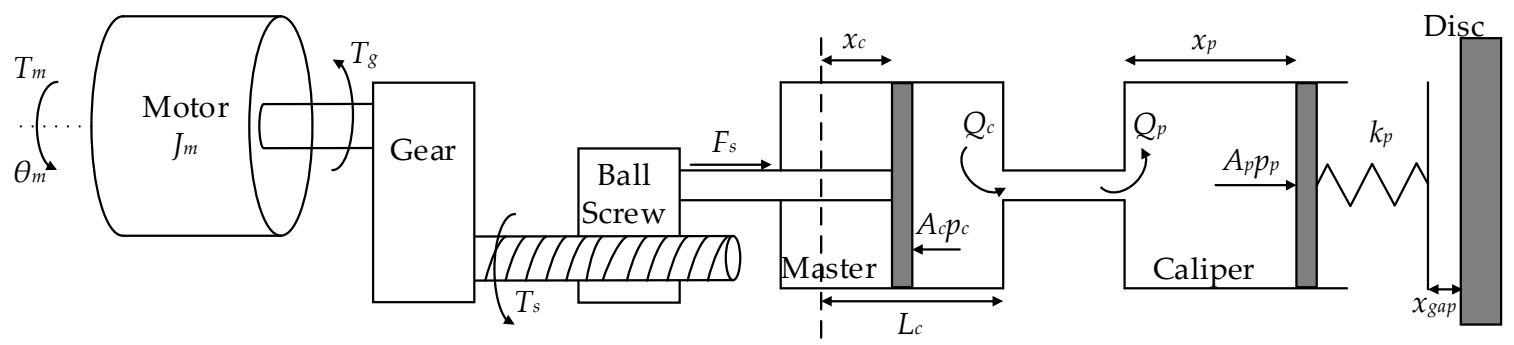

(b) Principle of hybrid brake-by-wire actuator

Figure 7. Hybrid brake-by-wire actuator. 


\subsubsection{Direct-Drive Electro-Hydraulic/ Electro-Mechanical Actuator}

Many teams have proposed their own BBW solutions, but no one solution has become the industry's technical consensus, as mentioned previously. Our team, combined with years of research experience, also proposed two BBW solutions that were based on linear motor technology, as shown in Figure 8. The first scheme uses the unequal-diameter hydraulic cylinder as a force amplification mechanism to amplify the thrust of linear motor; the second scheme uses unequal-arm lever as the amplification mechanism [37-39]. The linear motor converts electrical energy into axial electromagnetic force instead of torque, so these two schemes do not require motion conversion mechanism, such as ball-screw mechanism in EMB and EWB, thereby simplifying the structure and reducing the size [40].

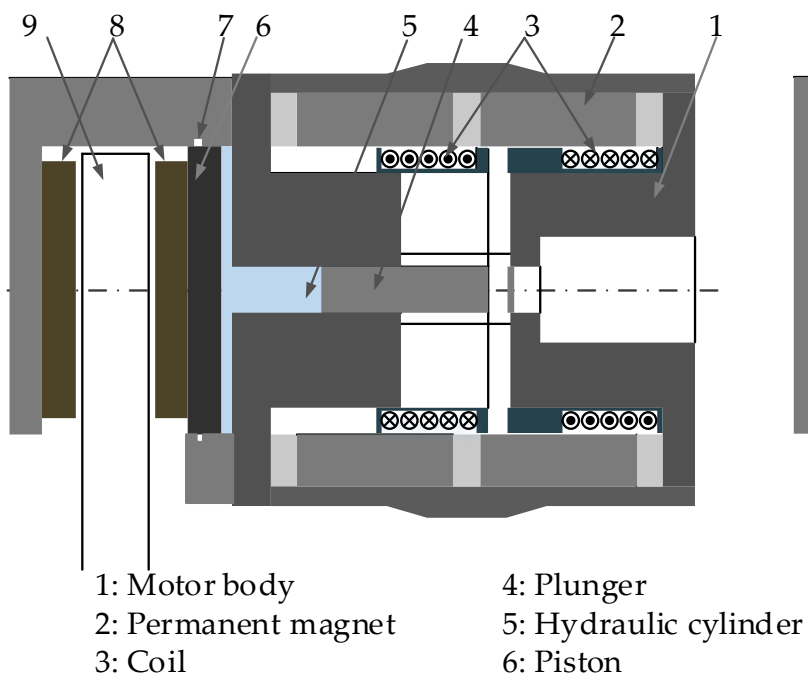

(a) Direct-drive electro-hydraulic actuator

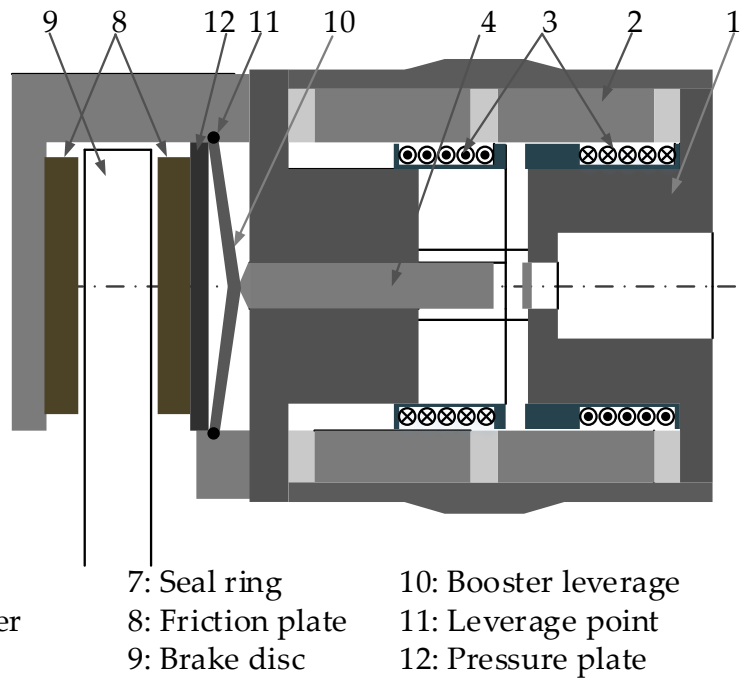

(b) Direct-drive electro-mechanical actuator

Figure 8. Direct-drive electro-hydraulic /electro-mechanical actuator.

In Figure 8a, 1 is the main body of linear motor, in which the permanent magnets 2 of Halbach arrangement are attached. When the coil 3 is energized, the energized coil is subjected to an electromagnetic force and then moves along the axis of linear motor due to the coil located in the magnetic field of magnets 2 . Plunger 4 is connected to the coil by a pin and it moves together with the coil. The motion (direction, displacement, and velocity) of plunger 4 is controlled by the magnitude and direction of the coil current. Two friction plates 8 are respectively symmetrically arranged on both sides of the brake disc 9 , the right plate is connected to the piston 6 , the left plate is closely connected to the brake caliper, and brake disc 9 is fixed on the wheel and it rotates with the wheel. When the plunger moves to the left, the brake fluid in the hydraulic cylinder 5 is compressed, and the high pressure liquid pushes the piston 6 to the left, thereby pushing the two friction plates to press the disc and provide braking force to the wheels [41,42].

The structure and principle of Figure $8 \mathrm{~b}$ are basically similar to Figure 8a. The main difference is that the enlarged structure is different, so it is not repeat here.

There are several types of BBW schemes that are summarized and described in this paper. Some of these schemes have been studied for many years and are relatively mature, such as EHB and EMB; some have just been proposed and they require more in-depth research. When compared with a traditional hydraulic brake, the technology of all BBW solutions is not mature enough to be practically applied in vehicles. However, with the continuous improvement of BBW, it is an inevitable trend to replace the traditional hydraulic brake from the perspective of long-term technology development. 


\subsection{The Composition of Brake-by-Wire System}

BBW can be applied to new energy vehicles, such as EV and HEV, as well as traditional internal combustion engine vehicles; however, it is more advantageous for new energy vehicles. Figure 9 shows the structure of BBW in EV. It mainly consists of four BBW actuators and corresponding controller and driver, brake pedal simulator, electronic control unit (ECU), battery, sensors, and cables. The entire BBW system is functionally divided into five subsystems [7]:

1. Four wheel actuators, such as EMB or EWB, described above.

2. Electronic pedal simulator and various sensors for converting the driver's braking action, velocity, wheel speeds, and other signals into electrical signals.

3. Energy management system for providing sufficient and stable electrical energy for actuator and control system.

4. Communication network for transmitting various electrical signals. Presently, the main communication network is usually CAN bus, and the auxiliary network is FlexRay bus.

5. Central ECU and actuator controller. ECU comprehensively calculates and processes all signals, and sends the brake force signal to actuator controller. The actuator controller regulates the actual braking force according to ECU signal and other necessary signals.

The pedal simulator converts the driver's braking action (stepping the brake pedal) into electrical signal by using force sensor or displacement sensor, and then transmits the signal to central ECU. The ECU first identifies the driver's braking request after receiving the brake signal, and then identifies the vehicle status based on signals of wheel speed sensors, power motor speed sensors, suspension load sensors, and so on. The target braking force of each wheel will be calculated and then transmitted to the actuator controller after comprehensive analysis of the above signals. Subsequently, the wheel BBW actuator provides the appropriate braking force under the control of actuator controller. Finally, all of the signals are feedback to the central ECU or actuator controller to control braking force accurately and in real-time [43].

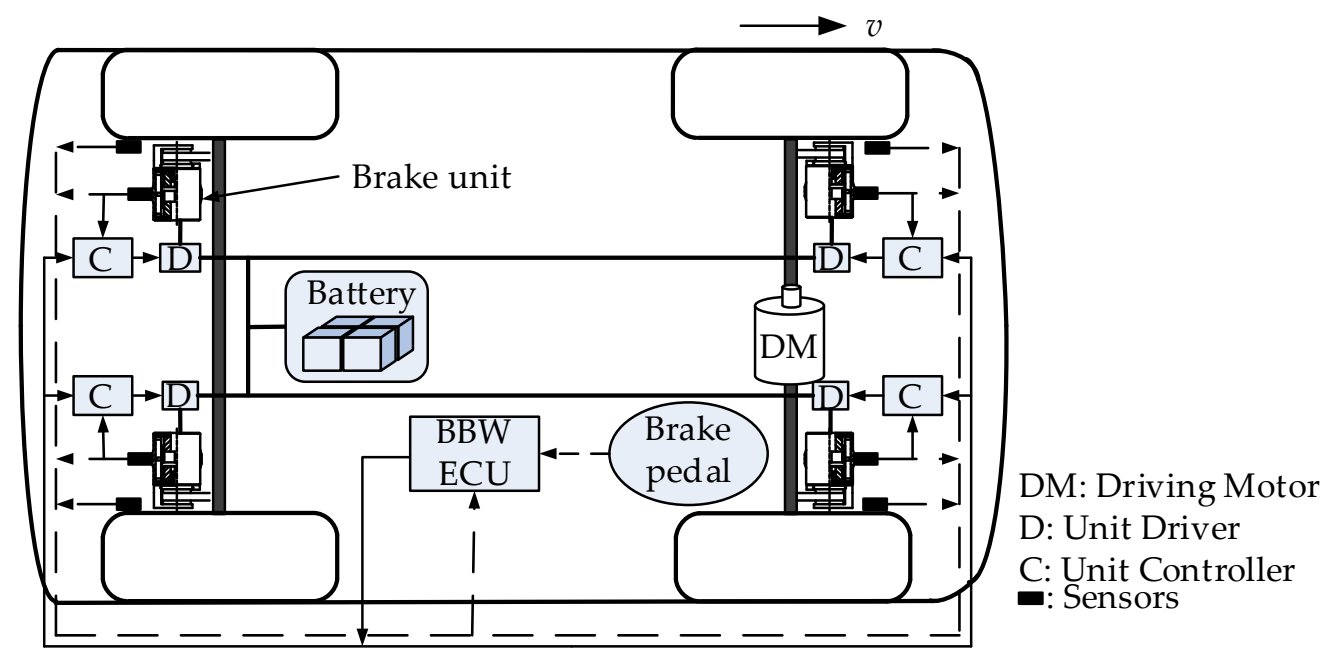

Figure 9. The structure of BBW in electric vehicle.

\subsection{Key Technologies of $B B W$}

From the development history of BBW actuator, it can be known that the technical difficulties and research focuses are mainly on the optimization design of actuators, coordinated control of braking force, and system redundancy design. 


\section{Design of brake actuator}

The actuator needs to provide clamping force of up to tens of thousands of Newtons in order to provide sufficient braking force [23]. However, the volume of the actuator must be as small as possible, and the mass must be as small as possible, due to the limitation of installation space. In particular, the front wheels need to be steered, so the volume must be strictly limited to prevent the actuator from interfering with the steering system.

2. Design of actuator controller

The braking process is short, which not only requires the driver to respond in time, but also requires the actuator to respond quickly [44]. However, the fast response and precise control are contradictory. The pursuit of fast response will inevitably lead to excessive overshooting of the braking force. Therefore, it is necessary to comprehensively consider the braking force control strategy in terms of fast response and precise control, and to find the best balance between them.

3. Design of redundant system

The BBW system eliminates the traditional mechanical or hydraulic connection between the pedal and actuator, and its communication system, control system, and hardware structure must be fault-tolerant [45]. Therefore, it is necessary to study the special requirements of BBW in detail, and propose a design, development, and manufacturing process to improve reliability.

BBW actuators are typical mechatronic components, where the schemes and technical concepts are very advanced. The research process is mainly divided into two steps: simulation and test verification. In the simulation phase, the professional software, such as Maxwell, AMESim, and Simulink, are used to establish the actuator's finite element model, dynamic model, and controller model, and the analysis tools and optimization theories are used to optimize the actuator and controller [26,46]. In the test phase, dSPACE is firstly used to complete software-in-the-loop (SIL) and hardware-in-the-loop (HIL) verification; and then, the actual vehicle test is completed to comprehensively evaluate the BBW system $[9,10,47,48]$.

\section{Control Technology of BBW}

The mechanical structure and braking principle of BBW are very different from the traditional hydraulic brake system, and the braking force regulation method is also completely different from the hydraulic system. The hydraulic brake system does not accurately control the wheel braking force. Most existing anti-lock braking systems use the "logic threshold control" instead of "slip rate control"; while, BBW can precisely control the wheel braking force and regulate the wheel slip rate. Therefore, BBW can greatly improve the braking capacity of vehicle.

\subsection{Parameter Estimation}

BBW can accurately control the braking force and braking posture of vehicle, but it is necessary to accurately obtain the vehicle speed, caliper force (the clamping force between the brake pad and brake disc), frictional resistance, brake gap, and so on, and then feed them back to the closed loop controller as feedback variables [49].

\subsubsection{Caliper Force/Braking Force Estimation}

There are two ways to obtain the caliper clamping force: direct measurement and indirect estimation. The EHB and hybrid BBW actuator can directly measure caliper force by measuring hydraulic pressure, and the Kalman filter can also be used to eliminate the sensor measurement noise and improve the data accuracy [46]. For indirect estimation, the caliper force is usually estimated from the piston position. In order to accurately estimate the caliper force, Todeschini designed a "position-pressure switching controller" to address the highly non-linearity between the piston position and hydraulic pressure [34], and adopted an adaptive algorithm to reduce the estimation error that is caused by temperature changes and friction plate wear [35]. There are also literatures that 
use estimation algorithms to estimate the hydraulic pressure change rate that cannot be indirectly measured and provide more feedback variables to the controller [46].

In EMB or EWB, some researchers use sensors to directly measure the caliper force $[44,50]$. However, it is more suitable to use a state monitor and estimation algorithm to estimate the caliper force (brake force) from the perspective of installation space and cost, while advanced algorithms can even simultaneously estimate other system parameters, such as wheel braking force, lateral tire force, plate friction coefficient, and frictional resistance [51].

The caliper force is a function of the friction plate displacement, which is called a caliper characteristic curve. The caliper force can be indirectly estimated by measuring the friction plate displacement or the motor rotor angular displacement and while using the brake dynamics model, caliper characteristic curves, and estimation algorithms [26,27,52]. The braking process is divided into non-contact state and contact state, according to whether the friction plate and brake disc are in contact. Kwak estimates the caliper force by establishing the two-state simplified model and corresponding caliper characteristic curve [53]. Park found that the characteristic curve between the caliper force and motor angular displacement is polynomial function, and the characteristic curves for forward and backward motion are generated by the least square method, respectively. The kissing point detection algorithm is also employed to make the characteristic curve similar to the actual clamping force that is measured by force sensor. If the friction plate wears for a long time and changes the caliper characteristic curve, the characteristic curve can be periodically updated to ensure the robustness of the estimation algorithm [17]. Hoseinnezhad designed a caliper force model that includes the Maxwell-slip friction hysteresis model, which can be used in conjunction with calibration techniques to update the "caliper force-displacement" characteristic curve in real time [54].

The thermocouple temperature sensor can be used to predict the brake disc temperature and the characteristic curve can be corrected based on the predicted temperature if the ambient temperature changes the characteristic curve [55]. In order to estimate the high dynamic caliper force, Saric uses the internal resolver and the dynamic stiffness relationship between the motor angle and clamp force to estimate the clamp force first; and then uses the motor current sensor, internal resolver, and torque balance method to estimate the caliper force again; the maximum-likelihood estimator was finally designed to fuse the outputs of two independent algorithms to optimize the caliper force estimation [56]. It should be noted that the internal resolver is absolute-angle sensor that needs to be integrated with the angle tracking observer to provide position and speed feedback variables for EMB. Hoseinnezhad designed a novel type of EMB angle-tracking observer that combines the linear time-invariant (LTI) observer and quadrature encoder [57]. Lee uses the output error method (OEM) and the prediction error method (PEM) to estimate parameters. such as caliper force, and compares the estimation accuracy with the evaluation speed. The best experimental trajectory experiment proves that PEM can provide better parameter estimation accuracy, but the estimation time is longer [58].

\subsubsection{Estimation and Compensation of Friction Force}

The actual caliper force lags behind the friction plate displacement or motor angular displacement due to friction resistance, phase lag effect, elastic characteristics of friction plate, and hysteresis characteristics of mechanical components [17,52]. These hysteresis characteristics have significant effects on braking performance, such as braking distance, braking time and average deceleration [59].

The cylinder friction of EHB is an important hysteresis factor. Dardanelli proposed a third-order linear model that is suitable for EHB pressure control, and identified the cylinder friction that is based on the model-based method. Finally, the dithering compensation technology was adopted to eliminate the negative effects of friction [36]. Castro simplified the original seven-state hybrid BBW actuator model into an uncertain second-order model, and explored the theory of model parameter linearization, the theory of function optimal approximation, and optimization technique to approximate the Stribeck friction model, which was subsequently used to control the brake pressure of hybrid BBW actuator [33]. 
Jo studied the friction characteristics of EMB motor, planetary gears, and ball screw, and found that the thread friction of ball screw is the main factor [60]. As the caliper force increases, the thread friction rapidly increases. If the caliper force is $30 \mathrm{kN}$, the friction that is generated by the ball screw, motor, and thrust bearing accounts for $48.9 \%, 21.4 \%$, and $17.9 \%$, respectively, of which the ball screw is the main source of friction [61]. Hoseinnezhad established the caliper force model, including Maxwell sliding friction model, and used the calibration technique to update the "caliper force-displacement" characteristic curve in real time [54]. For the nonlinear problems of friction, Lindvai-Soos considers friction as model uncertainty [62]. EWB is more sensitive to changes in the system parameters than EMB, because the wedge-shaped self-exciting mechanism also greatly amplifies the disturbances, such as frictional changes and temperature changes. Therefore, Park established the nonlinear fifth-order model of EWB, simplified the model by the singular perturbation method, and finally designed an adaptive control algorithm to accurately adjust the braking force [25].

\subsubsection{Estimation and Adjustment of Brake Gap}

The brake gap is the gap between the brake disc and the friction plate when not braking. If the brake gap is too small, the braking action cannot be completely cancelled; if the gap is too large, then the braking reaction time is too long, which directly threatens driving safety. As the friction plate wears, the brake gap becomes larger, so the brake actuator must have the ability to check and adjust the gap.

The braking process can be divided into contact state and disengaged state, according to whether the disc is in contact with the friction plate. Therefore, the switching timing of the two states can be detected or estimated, and then the braking gap can be subsequently adjusted according to the contact point [53]. Detecting of the abrupt change in motor current can determine whether the motor is blocked or not and, thus, can determine whether the brake gap is eliminated [60,63]. At the beginning of braking, it is judged whether the brake gap is eliminated by detecting the sudden change in current. If there is still a gap, perform a quick clearance elimination operation, and then enter the braking force real-time control operation. At the end of braking, first determine the critical point of the brake gap that is based on the current signal. Once the critical point is detected, a delay operation is set to generate a fixed braking gap by utilizing the motor characteristics [64].

\subsection{Control Method of Braking Force}

The braking process is very short, requiring not only the driver to react in time, but also the brake actuator to react quickly. However, the fast response and precise control are inherent contradictions. Too fast response will inevitably lead to excessive overshoot of the control variable. Therefore, the control strategy must consider fast response, precise control, and robustness requirements, and strive to find the best balance between them. Many researchers have proposed a variety of control methods that are suitable for BBW actuators, such as cascade control, fuzzy control, sliding mode variable structure control, and so on.

\subsubsection{Cascade Control}

The mathematical model of most BBW actuators can be simplified into a series model consisting of pressure/force loop, speed/position loop, and current loop. Therefore, the corresponding cascade control structure can be used to design the braking force controller.

Fabio Todeschini established a control-oriented series model for motorcycle's hybrid BBW actuator and designed an adaptive cascade controller. The inner-loop is a piston position loop, the outer-loop is a pressure loop, and the position loop works around the pressure loop. The position-pressure map estimation algorithm and model identification procedure were introduced to mitigate the non-linear effects that are caused by factors, such as temperature change and friction plate wear [34,35]. For the dead zone due to fluid reservoir and input saturation of hybrid BBW actuator, they further proposed a control architecture for dead zone and anti-windup compensation based on the simple algebraic calculation and the solution of linear matrix inequality (LMI) problem [32,33]. 
EMB and EWB are also typical three-loop systems that consist of force, position, and current. Line Chris considers that the standard three-closed-loop motion control method can meet the high dynamic requirements of EMB. For the non-linear load disturbance of braking force, the proportional integral (PI) control method of cascaded position, speed, and current are also feasible. Figure 10 shows the specific structure [65]. The outermost loop is braking force/caliper force PI controller, the middle loop is rotor speed PI controller, and the inner loop is current PI controller. For the challenges of nonlinear stiffness, actuator saturation, and load-related friction, they further used friction compensation, reverse gain scheduling, feedback linearization techniques, and motor torque prediction models to improve EMB performance [23]. In the design of the three-loop controller, the current loop is usually designed first, the speed loop is designed secondly by considering the current loop as a part of the speed regulation, and the force loop is then designed finally by considering the speed loop as a part of the force regulation loop [66].

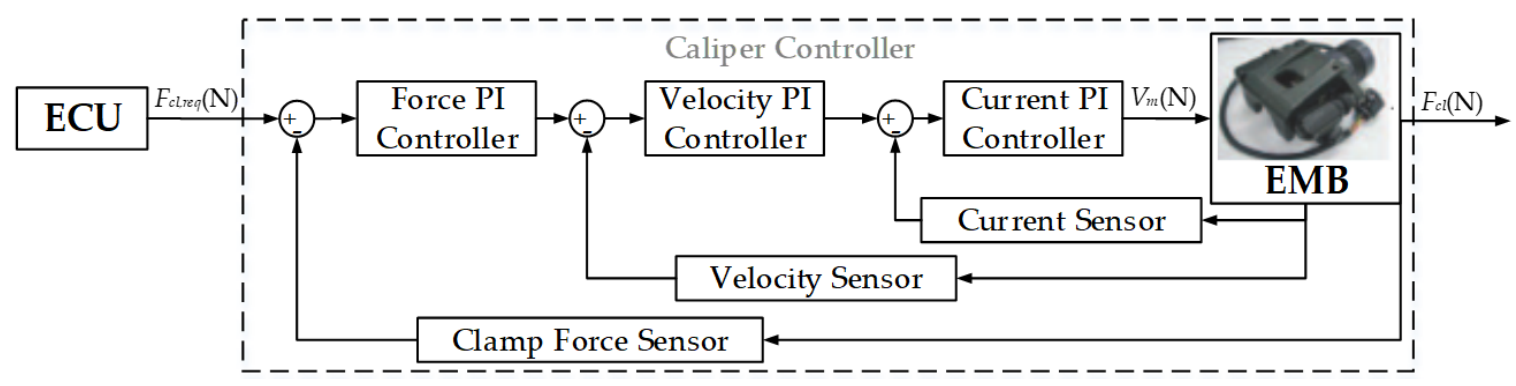

Figure 10. Cascade controller.

Ki et al. designed a similar cascade force/position control system with force sensor to control the EMB caliper force, and also designed the brake gap adjustment methods [52]. Baek uses cascaded current, speed, and position controller to regulate EMB's three-phase interior permanent magnet synchronous motor (IPMSM), and all control loops still use the proportional integral (PI) control method. However, the maximum torque per ampere (MTPA) control method is applied to the current controller to achieve high efficiency, the angle $\beta$ is calculated from the total input current, and the synchronous frame $d-q$ axis reference current is determined by the angle $\beta$. Consequently, the clamping force is increased by $19 \%$ at the same input current, and the total input power is reduced by approximately $40 \%$ at the same clamping force [67].

\subsubsection{Sliding Mode Control}

The BBW actuator has high nonlinearity and uncertainty due to the changes in environmental and system characteristics (such as temperature changes, pad wear, and nonlinear friction), so the sliding mode variable structure controller with sufficient robustness performance becomes the preferred control method for many researches $[27,33,68]$. For EHB, Ricardo de Castro designed a switching- $\sigma$ adaptive mechanism to attenuate the frictional disturbances through continuous sliding mode action. When compared with traditional dither-based friction compensation, the proposed controller can reduce the energy consumption of the actuator by more than $40 \%$ [33].

For EMB, Lindvai-Soos considered its friction as an uncertainty factor and designed a sliding mode controller (SMC) that was based on T-sum tuning rules, which compensates for frictional disturbances [62]. Lee proposed a robust near-time-optimal and state-constrained clamping force controller for EMB. The controller takes advantage of the motor capacity to achieve high closed-loop bandwidth. The time-optimal switching curve that is based on the maximum principle of Pontryagin is used as the switching surface, and the switching surface is used to schedule the control inputs based on the motor speed and positional offset. The robustness is achieved by introducing a boundary layer in the vicinity of the switching curve, which is robust and stable with bounded time-varying perturbations and modeling errors, and the tracking error asymptotically converges to the final boundary [44,69]. 
Peng proposed a fuzzy sliding mode controller (FSMC) based on wheel slip ratio due to the nonlinearity and uncertainty of EMB. For normal braking and emergency braking, the equivalent control law of SMC is designed according to the changes of the front and rear axle loads during braking, and the switching control law is adjusted by the fuzzy corrector. FSMC is more suitable for all types of roads with short braking distances when compared with the proportional integral and differential (PID) controller and traditional SMC [70].

EWB is more sensitive to changes in system parameters than EMB, such as the friction coefficient and temperature variation during braking, due to the characteristics of the wedge mechanism. Park first established the nonlinear fifth-order model of EWB, and then simplified the model while using the singular perturbation method. Finally, the pseudo-sliding mode adaptive control algorithm without clamping force sensor was designed based on the reduced-order model [25]. On the other hand, the wedge mechanism has a self-energizing effect, which can effectively reduce the motor current and can even be powered by 12-voltage battery. However, the EWB cannot be practically implemented unless the self-energizing effect is effectively controlled. In response to this problem, Han proposed the sliding mode controller with two structures, one using the estimated clamping force and the other using the measured clamping force, as shown in Figure 11 [26].

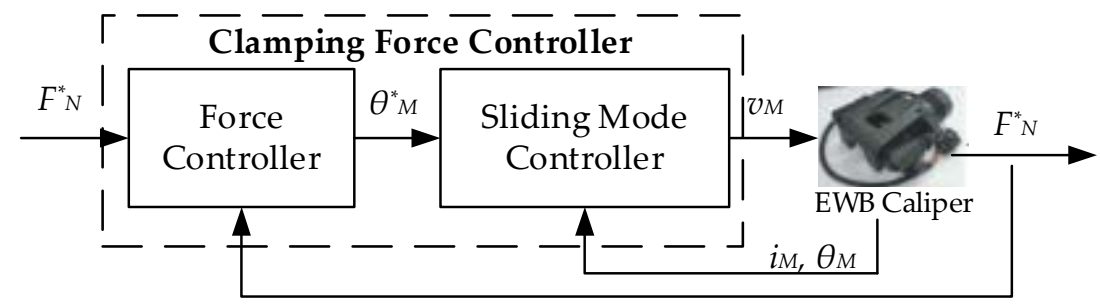

(a) Controller with measured clamping force

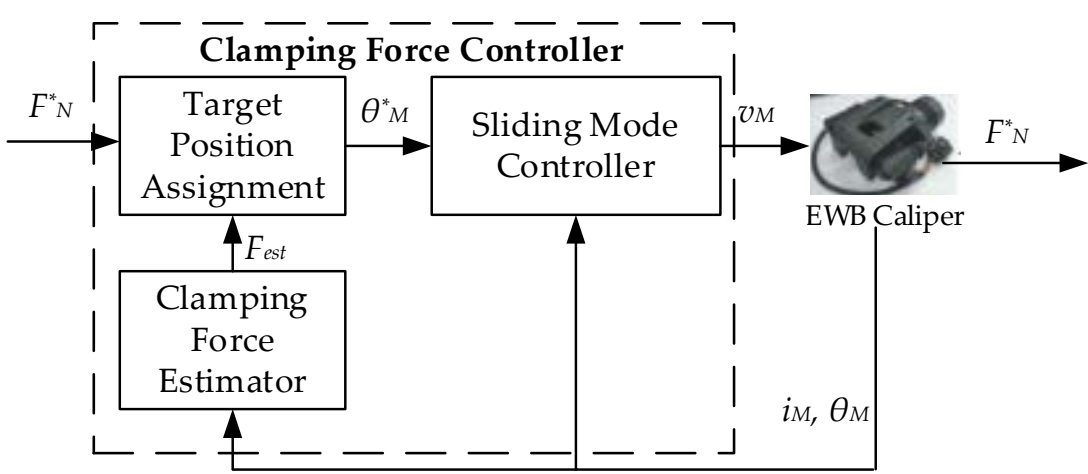

(b) Controller with estimated clamping force

Figure 11. Sliding mode controller.

In Figure 11, the estimated clamping force $F_{\text {est }}$ is obtained as:

$$
F_{\text {est }}=k_{c a l} \tan \theta_{\omega} \frac{P_{p s}}{2 \pi} \frac{1}{n_{g}} \bar{\theta}_{M}
$$

where: $k_{c a l}$ is caliper stiffness; $\theta_{\omega}$ is wedge angel; $P_{p s}$ is pitch of power; $n_{g}$ is gear ratio; and, $\bar{\theta}_{M}$ is rotational angle after the pad contact.

The sliding-mode control algorithm is proposed to achieve the robust control performance based on the estimated or measured clamping force. The controller output $i_{q}^{*}$ from the sliding mode controller can be expressed, as follows:

$$
i_{q}^{*}=i_{q e q}-k \operatorname{sgn}(s)
$$


where: $i_{\text {qeq }}$ and $k$ are the equivalent control current and control gain, respectively; $s$ is sliding surface for clamping force control, which is defined as the error between the current clamping force and desired clamping force.

\subsubsection{Fuzzy Control}

Although EMB has the advantages of good braking performance, fast braking response, and more accurate braking force, it also has strong nonlinearity, large load change, complicated control, and high risk of failure. The fuzzy controller that is based on fuzzy set theory, fuzzy variable, and fuzzy logic inference is essentially a nonlinear controller, which is robust to time-varying loads and widely used in BBW systems.

Kim is dedicated to the method of using fuzzy controller to accurately control the EMB clamping force under noise and disturbance conditions. The proposed fuzzy logic controller enables the EMB actuator to accurately follow the input target braking force [71]. Boquan designed the EMB controller that was based on FPGA and DSP Builder, in which FPGA is used to design peripheral circuits to implement the PWM control of motor, DSP Builder is used to design the fuzzy PID algorithm of the motor, and finally the hardware and software are combined to realize the overall control of EMB. The above method can effectively reduce the peripheral circuits and improve the stability of the control system [72]. Dinggen considers that it is not necessary to accurately control the clamping force. Instead, the controller, motor, and actuator can be considered as a closed-loop system, while the fuzzy controller is designed to indirectly adjust the clamping force with the slip rate as the control target. After eliminating the brake gap, the target slip rate is sent to the fuzzy controller to generate yhe PWM signal, which controls the motor electromagnetic torque, so that the wheel slip ratio is maintained at the target optimal slip ratio and the adhesion force between the wheel and road is maintained at the maximum value [63].

Peng proposed a fuzzy sliding mode control algorithm for normal braking and emergency braking based on the wheel slip ratio due to the uncertainty and nonlinearity of EMB, as shown in Figure 12 . The sliding mode equivalent control law is designed by combining with the dynamic changes of the front and rear axle loads during braking; and, the fuzzy corrector is used to adjust the sliding mode switching control law. The designed controller can quickly and smoothly reach the target value, has strong anti-disturbance ability, better adaptability to various working conditions, and has a positive effect on improving the stability of vehicle braking [73]. Kun uses EMB to achieve electronic brake force distribution (EBD) between the front and rear axles, and proposes an anti-lock braking (ABS) controller that is based on the fuzzy PID control algorithm, as shown in Figure 12. The results of three typical braking conditions show that the EMB-equipped vehicle can easily distribute the braking force according to the ideal braking force distribution rate, and the EMB-based ABS controller can accurately control the slip rate of each wheel and it has strong robustness [74].

Presently, the main research focuses on single-wheel anti-lock braking control. In fact, the fuzzy logic controller can be used for vehicle longitudinal and lateral stability control [75]. The target slip assignment algorithm that is based on fuzzy logic controller and direct yaw moment controller can also maintain the vehicle stability [51]. 


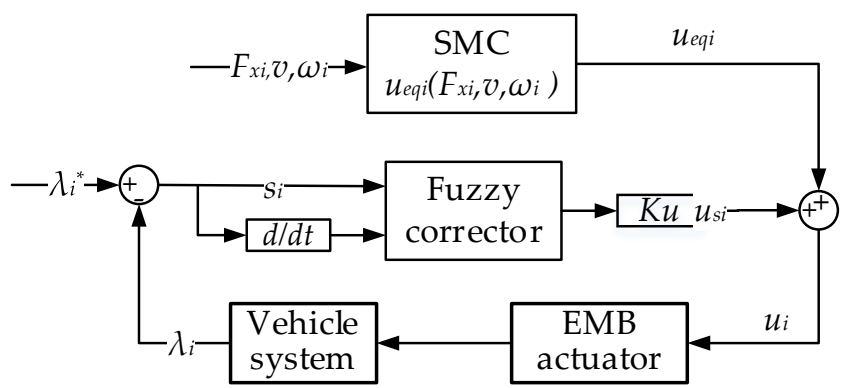

(a) Fuzzy SMC

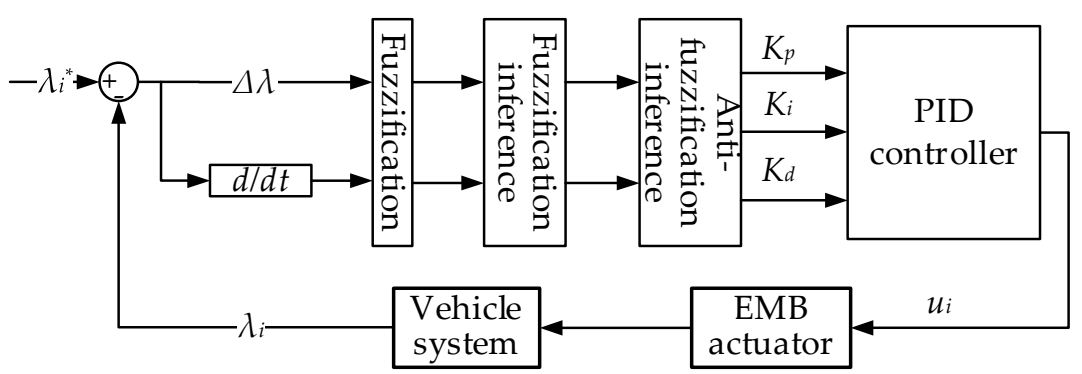

(b) Fuzzy PID

Figure 12. Diagram of fuzzy sliding mode controller (SMC) and fuzzy proportional integral and differential (PID).

\subsubsection{Other Control Methods}

The cascaded proportional-integral (PI) controller with fixed-gain limits the performance of EMB due to actuator saturation and non-linear friction and non-linear loads. Therefore, Chris Line proposed an improved control architecture to improve EMB performance by using inverse gain scheduling, friction compensation, feedback linearization, and model predictive control [23]. Xiaoxiang Gong designed the BBW actuator controller and driver based on TMS320F2812 digital signal processor. The state observer and double closed-loop anti-disturbance control algorithm were used to regulate the braking force. The experimental results show that the actuator response time is less than $15 \mathrm{~ms}$ and the braking force can be accurately adjusted, which indicates that it has good performance [46]. The robust fractional order controller (CRONE) has low sensitivity to noise and good robustness to challenges, such as parameter uncertainty, nonlinearity, and disturbance. Although the vehicle velocity and speed are variable, the wheel load and road adhesion coefficient are also changed, the ABS controller designed by CRONE can still accurately track the reference of wheel speed [76].

In light braking conditions, variations in the brake disc thickness can result in brake torque variations (BTV), which reduces the braking performance and driver satisfaction. Lee proposed a new method to directly attenuate braking jitter at the source by using the EMB's fast response capability. The EMB with high-bandwidth closed-loop caliper force tracking performance can actively compensate for the braking torque variations that are caused by the vibration. The first strategy is based on the linear parameter-variation (LPV) control structure, and the output regulation theory is used to schedule the angular speed and angular acceleration of the wheels. This method requires a high sampling rate, but experimental studies have shown good results. The second strategy uses adaptive feed forward compensation to schedule wheel angular position, speed, and acceleration. This method demonstrates lower sample rate requirements with better BTV attenuation capability, but it requires measuring the wheel position $[19,20]$.

\subsection{Redundancy of BBW System}

BBW systems, such as EMB or EWB, eliminate traditional mechanical or hydraulic connections between the pedal and wheel actuator, which are now replaced by cables and electronic devices with 
application software. Electronic systems are generally less reliable than mechanical systems [77]. BBW without mechanical redundancy might cause greater damage to occupants and other road participants than traditional hydraulic brake due to component failures. The reliability of BBW must be improved, otherwise it will be difficult to apply to vehicles [78]. Generally, there are three ways to improve the reliability and security of BBW. The first way is to improve the inherent reliability and reduce the failure probability by using reliability theory and reliability design methods [79]; the second way is to enable the BBW system have sufficient braking capability in the case of partial failure by using fault tolerant technology $[48,80,81]$; and, the third way is to detect and diagnose the fault in real time, and to remind the driver to repair the fault in time by fault diagnosis technology $[77,82]$.

\section{Application of BBW}

The BBW system abandons the principle and structure of hydraulic brake system, which can independently and accurately control the braking force of each wheel, and it can meet the requirements of high vehicle dynamics control. Therefore, the BBW system is easier to implement the vehicle postures control functions, such as ABS, ACC, and ESP; and, it is easier to match with the regenerative brake system of EV to recover more energy [83-86].

\subsection{Application of Anti-Lock Brake}

Presently, the BBW system has not been widely used in vehicles due to its imperfect maturity technology. Therefore, most researches on vehicle braking process focus on the anti-lock braking regulation that is based on the slip ratio $[63,73]$. The braking dynamics models that were established for slip rate controller mainly include $1 / 4$ vehicle model and 1/2 vehicle model; Peng first established a quarter-vehicle dynamics model for single-wheel slip rate control using a three-parameter tire model [87], and then established the half-vehicle dynamic model while considering wheel load transfer, which can be used for normal braking and emergency braking [70].

In the research of control methods, many researchers choose the sliding mode controller (SMC) to regulate the wheel slip rate, because it is very suitable for slip rate control and its performance is superior to the traditional logic threshold method [88]. For example, Peng designed the SMC to take full advantage of the ground adhesion after establishing a quarter-vehicle model. The fuzzy SMC is then designed to regulate the braking force after establishing of half-vehicle model in order to adapt to the variable of front and rear wheel load [70,87]. Zhao designed the SMC with the pulse width modulation (PWM) duty cycle variable based on wheel slip ratio. The results show that EMB has good stability, fastness, and sufficient robustness; and, the system dynamic performance with bipolar PWM is better than unipolar PWM [89]. When compared with the traditional logic threshold controller, the nonlinear SMC has good braking performance on low friction coefficient roads, which can effectively reduce the noise, vibration, and unevenness (NVH) of BBW, and it is stable in the sense of Lyapunov stability theory [90]. The pseudo-sliding mode mixed slip-deceleration (MSD) controller that is based on power law interpolation approximation has advantages in longitudinal slip-rate and vehicle deceleration control, which avoids chattering and ensures the sliding motion reachability under measurement noise and low sampling frequency $[84,91]$.

In addition to the SMC, the fuzzy controller is also used in the BBW anti-lock controller, which precisely controls the slip rate to its target value [74]. Shiao designed a general fuzzy logic controller (FLC) and a self-organizing fuzzy logic controller (SOFLC) to compare the anti-lock braking performance. The results show that SOFLC can adapt to different road conditions and it can effectively improve the braking performance to ensure driving stability by combining the road condition estimator (RCE) [92]. The fuzzy controller can form a fuzzy SMC together with the general SMC, and then adjust the switch control law through fuzzy corrector. The fuzzy SMC has superior performance and adaptability to various roads when compared with the PID controller and general SMC [70].

$\mathrm{BBW}$ is able to precisely adjust the braking force of each wheel, so that the braking force can be flexibly distributed between the axles or between the wheels $[75,93]$. The classic braking force 
distribution scheme of hydraulic brake system only considers the adhesion coefficient, while BBW can redistribute the braking force of the steering vehicle. The braking force between the front and rear axles is first distributed to prevent the rear wheels from locking, and the braking force between the inner and outer wheels is then distributed to improve the robustness of the braking process through sequential distribution [94]. In steering, the yaw stability is also critical to the overall safety of the vehicle. Anwar proposed a yaw stability controller that was based on the generalized predictive control (GPC) method, which predicts future yaw rate and then utilizes the flexibility and independence of BBW to take measures to stabilize the vehicle [95]. The extended Kalman filter is able to estimate the tire braking force, brake pad friction coefficient, and lateral tire force. It can be used in combination with the wheel slip controller and target slip distribution algorithm to maintain the vehicle stability during steering [51].

Tanelli designed a nonlinear output feedback control law for BBW, which can cope with input constraints and guarantees a restricted control effect, in order to ensure the braking reliability in the case of unknown road and wheel load variable. The controller determines the wheel state by detecting whether the slip ratio is in the unstable area of the friction curve, and then adjusts the setting parameters online to prevent the wheel from being locked [96]. Kim studied the optimal braking torque distribution between the regenerative braking system and EHB for HEV. The vehicle stability control algorithm that takes regenerative braking, EHB, and slip rate into account improves the braking performance, which results in shorter braking distances, smaller side slip angle errors, and yaw rate [97].

\subsection{Application in Electric Vehicles}

The regenerative braking system is a key technology for new energy vehicles, such as EV and HEV, which can significantly improve energy efficiency. BBW has inherent advantages in cooperating with regenerative braking system, because it can independently control the braking force of four wheels [21]. Therefore, BBW is very important in improving fuel consumption. Related research shows that the fuel efficiency of HEV equipped with EMB can be increased by $20 \%-50 \%$ [2]. The core issue of EV's brake system is how to distribute the braking force. The issue is divided into two levels: one is how to distribute the braking force between the BBW system and regenerative brake system; the second is how to distribute the braking force between the front and rear axles [42].

The brake system of HEV that was developed by Ko consists of a hydraulic brake system, EWB actuator, and regenerative brake system. The frictional braking force is provided by a hydraulic brake mounted on the rear wheels and EWB mounted on the front wheels; the power motor provides the regenerative braking force and it acts on the front wheels. If the stroke of brake pedal is less than the set threshold, the hydraulic brake on the rear wheel does not work and does not provide braking force, only the power motor provides regenerative braking force to the front wheels, or the power motor and EWB work simultaneously to provide braking force to the front wheels. If the pedal stroke is greater than the set threshold, the hydraulic brake, then EWB and power motor work simultaneously; and, the brake force distribution algorithm performs coordinated control between these brake systems to provide the required braking force $[98,99]$. The genetic algorithm is able to calculate the optimal distribution between regenerative braking torque and EHB torque for the given road friction coefficient and expected yaw moment. It can recover more braking energy than conventional regenerative braking systems that distribute regenerative braking torque and friction torque in a fixed ratio [100]. Under the premise of braking stability, the deceleration and slip rate controller based on the multi-layer fuzzy structure also improve the recovery efficiency. Under the same braking conditions, the braking distance and braking time are shortened by $12.19 \%$ and $15.54 \%$ when compared with the traditional ABS system; and, the recovery efficiency of light and heavy braking reached to $53 \%$ and $28 \%$, respectively [37].

EMB has the advantages of fast and accurate braking force adjustment, while the new energy buses have high-voltage power. Therefore, the new energy bus that is based on EMB can greatly improve energy efficiency. Kun proposed a braking force distribution strategy for EMB-based new 
energy bus while taking the braking rules, braking energy recovery rate, braking smoothness, critical powertrain capacity, and ABS performance into account, which includes the braking force distribution strategy between the axles and braking force distribution strategy between the drive wheels. EMB can meet the friction braking force adjustment requirements of the decoupled braking energy recovery system. When the braking force is distributed between the axles and between the wheels, the braking energy recovery strategy satisfies the driver's braking demand. In the typical urban conditions, Table 1 shows the performance comparison of electric buses that are equipped with different braking systems under no-load, half-load, $60 \%$ load, $80 \%$ load, and full load conditions. When compared with the bus without energy recovery system, the energy saved by this scheme is more than $36.48 \mathrm{~kW} \cdot \mathrm{h}$ at $100 \mathrm{~km}$, and the energy saving ratio is greater than $34.69 \%$; when compared with the conventional energy recovery system, the energy saved by this scheme is more than $17.73 \mathrm{~kW} \cdot \mathrm{h}$ at $100 \mathrm{~km}$, and the energy saving ratio is greater than $19.86 \%$ [101].

Table 1. km performance comparison between buses with different brake system.

\begin{tabular}{|c|c|c|c|c|c|c|c|}
\hline \multirow[b]{2}{*}{ Vehicle Load } & \multicolumn{3}{|c|}{$100 \mathrm{~km}$ Consumed Energy (kW·h) } & \multicolumn{2}{|c|}{ C Saved Energy (kW·h) } & \multicolumn{2}{|c|}{ C Improvement Ratio (\%) } \\
\hline & A & B & $\mathrm{C}$ & $\begin{array}{l}\text { Compared } \\
\text { with A }\end{array}$ & $\begin{array}{l}\text { Compared } \\
\text { with B }\end{array}$ & $\begin{array}{l}\text { Compared } \\
\text { with A }\end{array}$ & $\begin{array}{l}\text { Compared } \\
\text { with B }\end{array}$ \\
\hline No load & 95.67 & 76.92 & 59.19 & 36.48 & 17.73 & 38.17 & 23.05 \\
\hline Half load & 115.1 & 93.23 & 73.00 & 42.07 & 20.23 & 36.56 & 21.70 \\
\hline $60 \%$ load & 119.0 & 96.48 & 75.87 & 43.12 & 20.61 & 36.24 & 21.36 \\
\hline $80 \%$ load & 126.9 & 103.17 & 81.88 & 45.02 & 21.29 & 35.48 & 20.64 \\
\hline Full load & 135.0 & 109.98 & 88.14 & 46.81 & 21.84 & 34.69 & 19.86 \\
\hline \multicolumn{8}{|c|}{$\begin{array}{l}\text { A: Bus without recovery system } \\
\text { B: Bus with traditional recovery system } \\
\text { C: Bus with EMB recovery system }\end{array}$} \\
\hline
\end{tabular}

Most of the regenerative brake systems of EV are composed of electrical systems, such as motor, power inverters, and battery, but Ma proposed a new combined brake system structure, including power coordinate module, electro-hydraulic brake system, and hydraulic regenerative braking system, and designed a simple fuzzy control method to coordinate the high-pressure and low-pressure accumulators. The simulation found that the liquid capacity and initial SOC of the energy storage accumulator are the key factors affecting the energy recovery efficiency, and the initial braking velocity is the determining factor of the total recovery energy [102]. A conventional regenerative brake system needs to store the recovered energy in a energy storage device, such as battery or super capacitor, and then the storage device supplies the electric energy to other electric equipment. Therefore, the electric energy needs to be charged and discharged in two conversion processes, which reduces the energy utilization. If the braking energy that is recovered by generator is directly supplied to BBW actuator, such as EMB and EWB during braking, and only the excess energy is stored in the battery, it can reduce the conversion process of part energy, further improve the energy efficiency, and solve the problem of low energy recovery efficiency and low recovery power [103].

The EV that is equipped with regenerative braking system and BBW system can greatly improve energy efficiency, but they also face several challenges, such as inconsistent braking response, excessive control parameters, and complex structure. In response to these challenges, it is necessary to analyze the coupling model of regenerative braking system and BBW system and take the comprehensive braking performance of vehicle as the main system level object; while, the energy recovery efficiency and braking stability were treated as two disciplines. The optimal control parameters were obtained by coordinating the optimal recovery efficiency and the optimal braking stability [104]. The regenerative brake system changes the dynamic characteristics of EV, which results in unstable braking, especially when the ABS is triggered. The switching compensation control strategy while using sliding mode control can convert the complex coupled braking processes into independent control of friction braking and regenerative braking, and achieve a balance between braking performance, braking reliability, 
braking safety, and fuel economy [105]. The sudden change in brake torque can also give the driver an inconsistent braking feel when the brake mode is switched. The regenerated energy, braking sense consistency, and braking efficiency can be increased by $38.96 \%, 33.08 \%$, and $6.46 \%$, respectively, based on the multi-objective optimization model and particle swarm optimization (PSO) algorithm optimized braking system. Based on the compensation switching mode, the mean square errors of regenerative braking and $\mathrm{EHB}$ are reduced by $75.67 \%$ and $69.33 \%$, and the amplitude and steady-state errors are reduced by $25.89 \%$ and $9.83 \%$ than PID control, respectively, so the braking feel consistency is effectively improved [106].

\section{Conclusions and Prospects}

BBW systems, such as EHB, EMB, and EWB, provide faster, more accurate, and more flexible actuators for vehicle brake control. However, they require higher braking force control accuracy and higher robustness control algorithms. When compared with traditional brake system, the proportion of active control of BBW is higher and higher in the braking process. Therefore, the performance of the braking force control algorithm becomes the key factor for the precisely and rapidly adjustment of BBW system, and it is also the key factor for good match with vehicle.

In general, most existing BBW systems are still in the simulation verification and laboratory bench verification, and they are lacking in real vehicle verification. For the adaptability and robustness of system parameters change or external disturbances under the complex conditions, most of the control strategies and methods lack sufficient experimental verification Moreover, the brake comfort and steering stability are not discussed in depth, and the practicality and reliability of engineering practice are not considered. These problems have become an urgent challenge for the promotion and application of BBW systems.

Secondly, the research on anti-lock braking and braking force distribution strategy of EV that is based on BBW are still in the stage of simulation research and bench verification, because the technical maturity of BBW has not reached the level of actual vehicle equipment. Moreover, most of the current researches are limited to the regulation of wheel slip rate, and do not make full use of the advantages of BBW. It is necessary to conduct comprehensive researches on the braking and driving state control based on the BBW system, and implement the adjustment functions that are similar to ASR/ACC/ESP. For EV, the braking force can be provided by a regenerative brake system and BBW system. The coordinated control strategy of regenerative braking and BBW braking is worthy of further study to recover energy as much as possible while controlling the wheel slip rate.

Author Contributions: Conceptualization, X.G. (Xiaoxiang Gong) and W.G.; formal analysis, J.Y.; investigation, Y.Z.; writing-original draft preparation, X.G. (Xiaoxiang Gong) and X.G. (Xiangyu Gongye). All authors have read and agreed to the published version of the manuscript.

Funding: This research was funded by "Project of Science and Technology Research Program of Chongqing Education Commission of China, grant number, KJ1710240" and "Project of Science and Technology Research Program of Chongqing, grant number, cstc2018jcyjAX0746".

Conflicts of Interest: The authors declare no conflict of interest.

\section{References}

1. Yu, Z.; Han, W.; Xu, S.; Xiong, L. Review on Hydraulic Pressure Control of Electro-hydraulic Brake System. J. Mech. Eng. 2017, 53, 1-15. [CrossRef]

2. Ahn, J.K.; Jung, K.H.; Kim, D.H.; Jin, H.B.; Kim, H.S.; Hwang, S.H. Analysis of a regenerative braking system for Hybrid Electric Vehicles using an Electro-Mechanical Brake. Int. J. Automot. Technol. 2009, 10, 229-234. [CrossRef]

3. Hedenetz, B. Development framework for ultra-dependable automotive systems based on a time-triggered architecture. In Proceedings of the 1998 19th IEEE Real-Time Systems Symposium, Madrid, Spain, 2-4 December 1998; IEEE: Piscataway, NJ, USA, 1998. 
4. Ozdalyan, B. Development of a slip control anti-lock braking system model. Int. J. Automot. Technol. 2008, 9, 71-80. [CrossRef]

5. Joa, E.; Yi, K.; Sohn, K.; Bae, H. Four-wheel independent brake control to limit tire slip under unknown road conditions. Control Eng. Pract. 2018, 76, 79-95. [CrossRef]

6. Xiong, L.; Qian, C.; Yu, Z. Review on Composite Braking System of Electric Vehicle. Automob. Technol. 2015, $1,1-8$.

7. Gong, X. Research on Control Technology of a Novel Brake-by-Wire System for Electric Vehicle; Nanjing University of Science \& Technology: Nanjing, China, 2016.

8. Yang, K. Research of Electromechanical Brake and Vehicle Stability Control System for Light Vehicle; Jilin University: Changchun, China, 2009.

9. D'alfio, N.; Morgando, A.; Sorniotti, A. Electro-hydraulic brake systems: Design and test through hardware-in-the-loop simulation. Veh. Syst. Dyn. 2006, 44, 378-392. [CrossRef]

10. Yong, J.; Gao, F.; Ding, N.; He, Y. Design and validation of an electro-hydraulic brake system using hardware-in-the-loop real-time simulation. Int. J. Automot. Technol. 2017, 18, 603-612. [CrossRef]

11. Li, J.; Ding, M.; Yong, W.; Li, C. Evaluation and Optimization of the Nonlinear Flow Controllability of Switch Valve in Vehicle Electro-Hydraulic Brake System. IEEE Access 2018, 6, 31281-31293. [CrossRef]

12. Yu, Z.; Wang, J.; Lu, X.; Xu, S. Hydraulic pressure control of electro-hydraulic brake system. Control Theory Appl. 2016, 33, 897-902.

13. Zhang, F.; Wei, M. Multi-objective optimization of the control strategy of electric vehicle electro-hydraulic composite braking system with genetic algorithm. Adv. Mech. Eng. 2015, 7, 1687814014568491.

14. Yu, Z.; Yu, M.; Xiong, L. Modeling and Controlling of Vehicle ESP Wheel Cylinder Pressure Based on AMESim. Automob. Technol. 2013, 449, 19-22.

15. Mercorelli, P.; Werner, N. An Adaptive Resonance Regulator Design for Motion Control of Intake Valves in Camless Engine Systems. IEEE Trans. Ind. Electron. 2017, 64, 3413-3422. [CrossRef]

16. Shen, C.; Wang, J.; Lin, Y. Study on Brake Actuator of Electro-mechanical Braking System. Trans. Chin. Soc. Agric. Mach. 2007, 38, 30-33.

17. Park, G.; Choi, S.; Hyun, D. Clamping force estimation based on hysteresis modeling for electro-mechanical brakes. Int. J. Automot. Technol. 2017, 18, 883-890. [CrossRef]

18. Xia, L.; Deng, Z. Optimal design of electromechanical brake actuator through an integrated mechatronic approach. J. Jilin Univ. Eng. Technol. Ed. 2012, 42,1-9.

19. Lee, C.F.; Manzie, C. Active Brake Judder Attenuation Using an Electromechanical Brake-by-Wire System. IEEE/ASME Trans. Mechatron. 2016, 21, 2964-2976. [CrossRef]

20. Lee, C.F.; Manzie, C. Active Brake Torque Variation Compensation with Speed Scheduling of an Electromechanical Brake. In Proceedings of the FISITA World Automotive Congress, Beijing, China, 27-30 November 2012; Volume 5.

21. Cheon, J.S.; Kim, J.; Jeon, J. New Brake By Wire Concept with Mechanical Backup. SAE Int. J. Passeng. Cars Mech. Syst. 2012, 5, 1194-1198. [CrossRef]

22. Kim, J.; Jo, C.; Kwon, Y.; Cheon, J.S.; Park, S.J.; Jeon, G.B.; Shim, J. Electro-Mechanical Brake for Front Wheel with Back-up Braking. SAE Int. J. Passeng. Cars Mech. Syst. 2014, 7, 1369-1373. [CrossRef]

23. Line, C.; Manzie, C.; Malcolm, G.C. Electromechanical Brake Modeling and Control: From PI to MPC. IEEE Trans. Control Syst. Technol. 2008, 16, 446-457. [CrossRef]

24. Liu, G.; Song, J. Hardware-in-the-loop Test Bench for Electromechanical Brake System. Automot. Eng. 2006, 28, 929-932.

25. Park, H.; Choi, S.B. Development of a Sensorless Control Method for a Self-Energizing Brake System Using Noncircular Gears. IEEE Trans. Control Syst. Technol. 2013, 21, 1328-1339. [CrossRef]

26. Han, K.; Kim, M.; Huh, K. Modeling and control of an electronic wedge brake. Proc. Inst. Mech. Eng. Part C J. Mech. Eng. Sci. 2012, 226, 2440-2455. [CrossRef]

27. Han, K.; Huh, K.; Hwang, W. EWB Control Based on the Estimated Clamping Force. In Proceedings of the SAE 2012 Brake Colloquium \& Exhibition-30th Annual 2012, San Diego, CA, USA, 23-26 September 2012; SAE International: Warrendale, PA, USA, 2012; p. 2012-01-1797.

28. Shin, D.H.; Lee, S.; Jeong, C.P.; Kwon, O.S.; Park, T.S.; Jin, S.H.; Ban, D.H.; Yang, S.H. Analytic approaches for keeping high braking efficiency and clamping efficiency of electro wedge brakes. Int. J. Precis. Eng. Manuf. 2015, 16, 1609-1615. [CrossRef] 
29. Amirhossein, G.; Reza, K. A New Approach to the Electronic Wedge Brake. In Proceedings of the SAE 2012 Brake Colloquium \& Exhibition-30th Annual 2012, San Diego, CA, USA, 23-26 September 2012; SAE International: Warrendale, PA, USA, 2012; p. 2012-01-1801.

30. Jo, C.H.; Lee, S.M.; Song, H.L.; Cho, Y.S.; Hyun, D.Y.; Kin, H.S. Design and Control of an Upper-Wedge -Type Electronic Brake. Proc. Inst. Mech. Eng. Part D J. Automob. Eng. 2010, 224, 1393-1405. [CrossRef]

31. Shin, D.H.; Kwon, O.S.; Moon, J.I.; Yang, S.H. Cost-Effective Approaches of Circumferential Electro Wedge Brake for Reducing Unbalance-Wears. J. Mech. Eng. Autom. 2012, 2, 208-212.

32. Todeschini, F.; Formentin, S.; Panzani, G.; Corno, M.; Savaresi, S.M.; Zaccarian, L. Nonlinear Pressure Control for BBW Systems via Dead-Zone and Antiwindup Compensation. IEEE Trans. Control Syst. Technol. 2016, 24, 1419-1431. [CrossRef]

33. Castro, R.D.; Todeschini, F.; Araújo, R.E.; Savaresi, S.M.; Corno, M.; Freitas, D. Adaptive-robust friction compensation in a hybrid brake-by-wire actuator. Proc. Inst. Mech. Eng. Part I J. Syst. Control Eng. 2014, 228, 769-786. [CrossRef]

34. Todeschini, F.; Corno, M.; Panzani, G.; Savaresi, S.M. Adaptive position-pressure control of a brake by wire actuator for sport motorcycles. Eur. J. Control 2014, 20, 79-86. [CrossRef]

35. Todeschini, F.; Corno, M.; Panzani, G.; Fiorenti, S.; Savaresi, S.M. Adaptive Cascade Control of a Brake-by-Wire Actuator for Sport Motorcycles. IEEE/ASME Trans. Mechatron. 2015, 20, 1310-1319. [CrossRef]

36. Dardanelli, A.; Alli, G.; Savaresi, S.M. Modeling and control of an electro-mechanical brake-by-wire actuator for a sport motorbike. IFAC Proc. Vol. 2010, 43, 524-531. [CrossRef]

37. Gong, X.; Chang, S.; Jiang, L.; Li, X. Braking Method of Electric Vehicle Based on Direct Drive ElectroHydraulic Brake Unit. Open Mech. Eng. J. 2015, 9, 351-360. [CrossRef]

38. Gong, X.; Chang, S.; Jiang, L.; Li, X. A Novel Brake-by-Wire Unit and Control System for Electric Vehicle. J. Shanghai Jiao Tong Univ. 2016, 50, 395-400.

39. Gong, X.; Ge, W.; Wang, L. A Brake-by-Wire Unit for Electric Vehicle; C.T.G. University: China, Chongqing, 2017.

40. Zhang, J.; Liu, X.; Shi, Z. Design and Analysis of a Linear Generator with Improved Halbach PM Arrays. Small Spec. Electr. Mach. 2018, 46, 23-26.

41. Gong, X.; Chang, S.; Jiang, L.; Li, X. Research on regenerative technology of EV based on direct-drive electric-hydraulic brake unit. In Proceedings of the 2015 IEEE International Conference on Mechatronics and Automation (ICMA), Beijing, China, 2-5 August 2015.

42. Gong, X.; Chang, S.; Jiang, L.; Li, X. Research on regenerative brake technology of electric vehicle based on direct-drive electric-hydraulic brake system. Int. J. Veh. Des. 2016, 70, 1-28. [CrossRef]

43. Li, X.; Chang, S.; Gong, X. Modeling of a new brake by wire system based on the direct-drive electro-hydraulic brake unit. In Proceedings of the 2015 IEEE Advanced Information Technology, Electronic and Automation Control Conference (IAEAC), Chongqing, China, 19-20 December 2015.

44. Lee, C.F.; Manzie, C. High-Bandwidth Clamp Force Control for an Electromechanical Brake. SAE Int. J. Passeng. Cars Electron. Electr. Syst. 2012, 5, 590-599. [CrossRef]

45. Leu, K.; Huang, H.; Chen, Y.Y.; Huang, L.R.; Ji, K.M. An intelligent brake-by-wire system design and analysis in accordance with ISO-26262 functional safety standard. In Proceedings of the 2015 International Conference on Connected Vehicles and Expo (ICCVE), Shenzhen, China, 19-23 October 2015.

46. Gong, X.; Qian, L.; Ge, W.; Wang, L. Research on the Anti-Disturbance Control Method of Brake-by-Wire Unit for Electric Vehicles. World Electr. Veh. J. 2019, 10, 44. [CrossRef]

47. Liao, J.; Wang, J. Research on the braking performance of electro-mechanical brake based on the hardware-in-the-loop simulation. Mechatron. Eng. Technol. 2009, 38, $26-29$.

48. Lee, K.J.; Kwon, J.M.; Cheon, J.S.; Ahn, H.S. Hardware-in-the-Loop Simulation of Brake-by-Wire Systems with FlexRay Communication. In Proceedings of the 32nd Annual SAE Brake Colloquium \& Exhibition, Burlingame, CA, USA, 5-8 October 2014; SAE International: Detroit, MI, USA.

49. Semmler, S.; Fischer, D.; Isermann, R.; Schwarz, R.; Rieth, P. Estimation of vehicle velocity using brake-by-wire actuators. IFAC Proc. Vol. 2002, 35, 169-174. [CrossRef]

50. Werner, B.; Aleksandar, V.; Gordana, P.; Oscar, D.M. Micro Torque Measurement Based on the Cable Brake Principle. In Proceedings of the First IEEE International Conference on Sensors-IEEE Sensors 2002, Orlando, FL, USA, 12-14 June 2002; Institute of Electrical and Electronics Engineers Inc: Piscataway, NJ, USA, 2002. 
51. Hong, D.; Hwang, I.; Yoon, P.; Huh, K. Development of a Vehicle Stability Control System Using Brake-by-Wire Actuators. J. Dyn. Syst. Meas. Control 2008, 130, 011008. [CrossRef]

52. Ki, Y.H.; Lee, K.J.; Cheon, J.S.; Ahn, H.S. Design and implementation of a new clamping force estimator in Electro-Mechanical Brake systems. Int. J. Automot. Technol. 2013, 14, 739-745. [CrossRef]

53. Kwak, J.; Yao, B.; Bajaj, A. Analytical Model Development and Model Reduction for Electromechanical Brake System. In Proceedings of the 2004 ASME International Mechanical Engineering Congress and Exposition 2004, Anaheim, CA, USA, 13-19 November 2004; p. 61955.

54. Hoseinnezhad, R.; Bab-Hadiashar, A.; Rocco, T. Real-Time Clamp Force Measurement in Electromechanical Brake Calipers. IEEE Trans. Veh. Technol. 2008, 57, 770-777. [CrossRef]

55. Saric, S.; Bab-Hadiashar, A.; Walt, J.V.D. Estimating clamp force for brake-by-wire systems: Thermal considerations. Mechatronics 2009, 19, 886-895. [CrossRef]

56. Saric, S.; Bab-Hadiashar, A.; Hoseinnezhad, R. Clamp-Force Estimation for a Brake-by-Wire System: A Sensor-Fusion Approach. IEEE Trans. Veh. Technol. 2008, 57, 778-786. [CrossRef]

57. Hoseinnezhad, R. Position sensing in brake-by-wire callipers using resolvers. IEEE Trans. Veh. Technol. 2006, 55, 924-932. [CrossRef]

58. Lee, C.F.; Manzie, C. Rapid parameter identification for an electromechanical brake. In Proceedings of the 2013 Australian Control Conference, Perth, WA, Australia, 4-5 November 2013; IEEE Computer Society: Piscataway, NJ, USA, 2013.

59. Shyrokau, B.; Wang, D.; Augsburg, K.; Ivanov, V. Vehicle dynamics with brake hysteresis. Proc. Inst. Mech. Eng. Part D J. Automob. Eng. 2013, 227, 139-150. [CrossRef]

60. Jo, C.; Hwang, S.; Kim, H. Clamping-Force Control for Electromechanical Brake. IEEE Trans. Veh. Technol. 2010, 59, 3205-3212. [CrossRef]

61. Xia, L.; Deng, Z. Calculation and Analysis of Friction Torque and Energy Dissipation of Electromechanical Brake Actuator. J. Hunan Univ. Nat. Sci. 2018, 45, 48-56.

62. Lindvai-Soos, D.; Horn, M. Modelling, control \& implementation of an electro-mechanic braking force actuator for HEV and EV. IFAC Proc. Vol. 2013, 46, 620-625.

63. Li, D.; Zhang, L.; He, B. Fuzzy Control Based on Vehicle Slip-ratio for Electro-mechanical Braking Systems. J. Mech. Eng. 2012, 48, 124-129. [CrossRef]

64. Ge, Z.; Wang, W.; Wang, J. Control strategy for brake clearance adjustment of electronic mechanical brake. J. Zhejiang Univ. Eng. Sci. 2017, 51, 138-144.

65. Line, C.; Manzie, C.; Good, M. Control of an Electromechanical Brake for Automotive Brake-by-Wire Systems with an Adapted Motion Control Architecture. In Proceedings of the SAE 2004 Automotive Dynamics, Stability \& Controls Conference and Exhibition, Burlingame, PA, USA, 5-8 October 2004; SAE International: Warrendale, PA, USA, 2004; p. 2004-01-2050.

66. Yang, K.; Li, J.; Guo, L.; Li, Y. Design and Simulation of Electromechanical Brake System. Trans. Chin. Soc. Agric. Mach. 2008, 39, 24-27.

67. Baek, S.K.; Oh, H.K.; Park, J.H.; Shin, Y.J.; Kin, S.W. Evaluation of Efficient Operation for Electromechanical Brake Using Maximum Torque per Ampere Control. Energies 2019, 12, 1869. [CrossRef]

68. Atia, M.R.A.; Haggag, S.A.; Kamal, A.M.M. Enhanced Electromechanical Brake-by-Wire System Using Sliding Mode Controller. J. Dyn. Syst. Meas. Control 2016, 138. [CrossRef]

69. Lee, C.F.; Manzie, C. Near-time-optimal tracking controller design for an automotive electromechanical brake. Proc. Inst. Mech. Eng. Part I J. Syst. Control Eng. 2011, 226, 537-549. [CrossRef]

70. Peng, X.; He, L.; Lv, Y. Fuzzy sliding mode control based on vehicle slip ratio for electro-mechanical braking systems. J. Cent. South Univ. Sci. Technol. 2018, 49, 360-370.

71. Kim, K.; Li, Q.; Park, C.; Hwang, K. A Design of Intelligent Actuator Logic using Fuzzy Control for EMB System. In Proceedings of the International MultiConference of Engineers and Computer Scientists, Hong Kong, China, 16-18 March 2011.

72. Li, B.; Tian, H.S.; Wang, R.; Dong, X.; Zhang, X. Design of torque motor controller in EMB based on FPGA. Mach. Des. Manuf. 2010, 6, 9-11.

73. Peng, X.; Jia, M.; He, L.; Yu, X.; Lv, Y. Fuzzy sliding mode control based on longitudinal force estimation for electro-mechanical braking systems using BLDC motor. CES Trans. Electr. Mach. Syst. 2018, 2, 142-151.

74. Yang, K.; Li, J.; Li, Y.; Tan, S.; Wei, Q.; Tang, L. Study of EBD/ABS Based on Electromechanical Brake System. J. Syst. Simul. 2009, 21, 1785-1788. 
75. Xiang, W.; Richardson, P.C.; Zhao, C.; Mohammad, S. Automobile Brake-by-Wire Control System Design and Analysis. IEEE Trans. Veh. Technol. 2008, 57, 138-145. [CrossRef]

76. Benine-Neto, A.; Moreau, X.; Lanusse, P. Robust control for an electro-mechanical anti-lock braking system: The CRONE approach. IFAC-PapersOnLine 2017, 50, 12575-12581. [CrossRef]

77. Hwang, W.; Huh, K. Fault Detection and Estimation for Electromechanical Brake Systems Using Parity Space Approach. J. Dyn. Syst. Meas. Control 2014, 137. [CrossRef]

78. Milanés, V.; González, C.; Naranjo, J.E.; Onieva, E.; De Pedro, T. Electro-hydraulic braking system for autonomous vehicles. Int. J. Automot. Technol. 2010, 11, 89-95. [CrossRef]

79. Lee, K.J.; Ki, Y.H.; Cheon, J.S.; Hwang, G.; Ahn, H.S. Approach to functional safety-compliant ECU design for electro-mechanical brake systems. Int. J. Automot. Technol. 2014, 15, 325-332. [CrossRef]

80. Liu, H.; Deng, W.; He, R.; Wu, J.; Zhu, B. Fault-Tolerant Control of Brake-by-Wire Systems Based on Control Allocation. In Proceedings of the SAE 2016 World Congress and Exhibition, Detroit, MI, USA, 12-14 April 2016; SAE International: Warrendale, PA, USA, 2016; p. 2016-01-0132.

81. Hermann, K.; Gunther, B.; Stefan, P. Tolerating arbitrary node failures in the time-triggered architecture. In Proceedings of the SAE 2001 World Congress, Detroit, MI, USA, 5-8 March 2001; SAE International: Warrendale, PA, USA, 2001.

82. Wang, Z.; Yu, L.; You, C.; Wang, Y.; Song, J. Fail-safe control allocation for a distributed brake-by-wire system considering the driver's behaviour. Proc. Inst. Mech. Eng. Part D J. Automob. Eng. 2014, 228, 1547-1567. [CrossRef]

83. Anwar, S.; Zheng, B. An Antilock-Braking Algorithm for an Eddy-Current-Based Brake-by-Wire System. IEEE Trans. Veh. Technol. 2007, 56, 1100-1107. [CrossRef]

84. Tanelli, M.; Sartori, R.; Savaresi, S.M. Sliding mode slip-deceleration control for brake-by-wire control systems. IFAC Proc. Vol. 2007, 40, 135-142. [CrossRef]

85. Cheon, J.S. Brake by Wire System Configuration and Functions using Front EWB (Electric Wedge Brake) and Rear EMB (Electro-Mechanical Brake) Actuators. SAE Tech. Pap. Ser. 2010. [CrossRef]

86. Kun, Y.; Li, J.; Li, Y.; Rong, R.; Tan, S.; Guo, L. Application of Electromechanical Brake System in Ada ptive Cruise Control. Trans. Chin. Soc. Agric. Mach. 2008, 39, 34-38.

87. Peng, X.; Chen, C.; Zhang, J. Study of the Sliding Mode Control of Electromechanical Brake Systems. J. Hunan Univ. Nat. Sci. 2010, 37, 35-39.

88. Zhou, S.; Chen, Q.; Sun, D. Variable Structure Control with Sliding Mode for ABS of Vehicle Based on EMB System. J. Northeast. Univ. Nat. Sci. 2016, 37, 994-997.

89. Zhao, G.; Wei, M. Effect of the Characteristics of Power Supply on the Anti-lock Braking Behaviors of a Brake-by-wire System. Mech. Sci. Technol. Aerosp. Eng. 2011, 30, 108-111.

90. Anwar, S. Anti-Lock Braking Control of a Hybrid Brake-by-Wire System. Proc. Inst. Mech. Eng. Part D J. Automob. Eng. 2006, 220, 1101-1117. [CrossRef]

91. Tanelli, M.; Sartori, R.; Savaresi, S.M. Combining Slip and Deceleration Control for Brake-by-wire Control Systems: A Sliding-mode Approach. Eur. J. Control 2007, 13, 593-611. [CrossRef]

92. Shiao, Y.; Nguyen, Q.A.; Lin, J.W. A Study of Novel Hybrid Antilock Braking System Employing Magnetorheological Brake. Adv. Mech. Eng. 2014, 2014, 617584. [CrossRef]

93. Suzuki, Y.; Kano, Y.; Abe, M. A study on tyre force distribution controls for full drive-by-wire electric vehicle. Veh. Syst. Dyn. 2014, 52 (Suppl. S1), 235-250. [CrossRef]

94. Zhang, L.; Yu, L.; Wang, Z.; Zuo, L.; Song, L. All-Wheel Braking Force Allocation During a Braking-in-Turn Maneuver for Vehicles With the Brake-by-Wire System Considering Braking Efficiency and Stability. IEEE Trans. Veh. Technol. 2016, 65, 4752-4767. [CrossRef]

95. Anwar, S. Generalized predictive control of yaw dynamics of a hybrid brake-by-wire equipped vehicle. Mechatronics 2005, 15, 1089-1108. [CrossRef]

96. Tanelli, M.; Astolfi, A.; Savaresi, S.M. Robust nonlinear output feedback control for brake by wire control systems. Automatica 2008, 44, 1078-1087. [CrossRef]

97. Kim, D.; Kim, C.; Hwang, S.; Kim, H. Hardware in the Loop Simulation of Vehicle Stability Control using Regenerative Braking and Electro Hydraulic Brake for Hybrid Electric Vehicle. IFAC Proc. Vol. 2008, 41, 5664-5669. [CrossRef] 
98. Ko, J.; Ko, S.; Son, H.; Yoo, B.; Cheon, J.; Kim, H. Development of Brake System and Regenerative Braking Cooperative Control Algorithm for Automatic-Transmission-Based Hybrid Electric Vehicles. IEEE Trans. Veh. Technol. 2015, 64, 431-440. [CrossRef]

99. Ko, J.; Ko, S.; Bak, Y.; Jang, M.; Yoo, B.; Cheon, J.; Kim, H. Development of regenerative braking co-operative control system for automatic transmission-based hybrid electric vehicle using electronic wedge brake. In Proceedings of the 2013 World Electric Vehicle Symposium and Exhibition (EVS27), Barcelona, Spain, 17-20 November 2013.

100. Kim, D.H.; Kim, J.M.; Hwang, S.H.; Kim, H.S. Optimal brake torque distribution for a four-wheeldrive hybrid electric vehicle stability enhancement. Proc. Inst. Mech. Eng. Part D J. Automob. Eng. 2007, 221, 1357-1366. [CrossRef]

101. Yang, K.; Gao, S.; Wang, J.; Li, J.; Liu, R.; Xu, J.C. A Study of Decoupled Brake Energy Recovery System Based on Electro-mechanical Brake. Automot. Eng. 2016, 38, 1072-1079.

102. Ma, B.; Lin, M.; Chen, Y.; Wang, L. Investigation of energy efficiency for electro-hydraulic composite braking system which is based on the regenerated energy. Adv. Mech. Eng. 2016, 8, 1687814016666449. [CrossRef]

103. Wang, Z.; Ma, C.; Wang, F. An Analysis on the Braking Energy Regeneration in Electro-mechanical Braking System. Automot. Eng. 2010, 32, 972-976.

104. He, C.; Wang, G.; Gong, Z.; Xing, Z.; Xu, D. A Control Algorithm for the Novel Regenerative-Mechanical Coupled Brake System with by-Wire Based on Multidisciplinary Design Optimization for an Electric Vehicle. Energies 2018, 11, 2322. [CrossRef]

105. Li, L.; Li, X.; Wang, X.; Liu, Y.; Song, J.; Ran, X. Transient switching control strategy from regenerative braking to anti-lock braking with a semi-brake-by-wire system. Veh. Syst. Dyn. 2016, 54, 231-257. [CrossRef]

106. Wang, C.; Zhao, W.; Li, W. Braking sense consistency strategy of electro-hydraulic composite braking system. Mech. Syst. Signal Process. 2018, 109, 196-219. [CrossRef]

(C) 2020 by the authors. Licensee MDPI, Basel, Switzerland. This article is an open access article distributed under the terms and conditions of the Creative Commons Attribution (CC BY) license (http://creativecommons.org/licenses/by/4.0/). 